BMC

Plant Biology

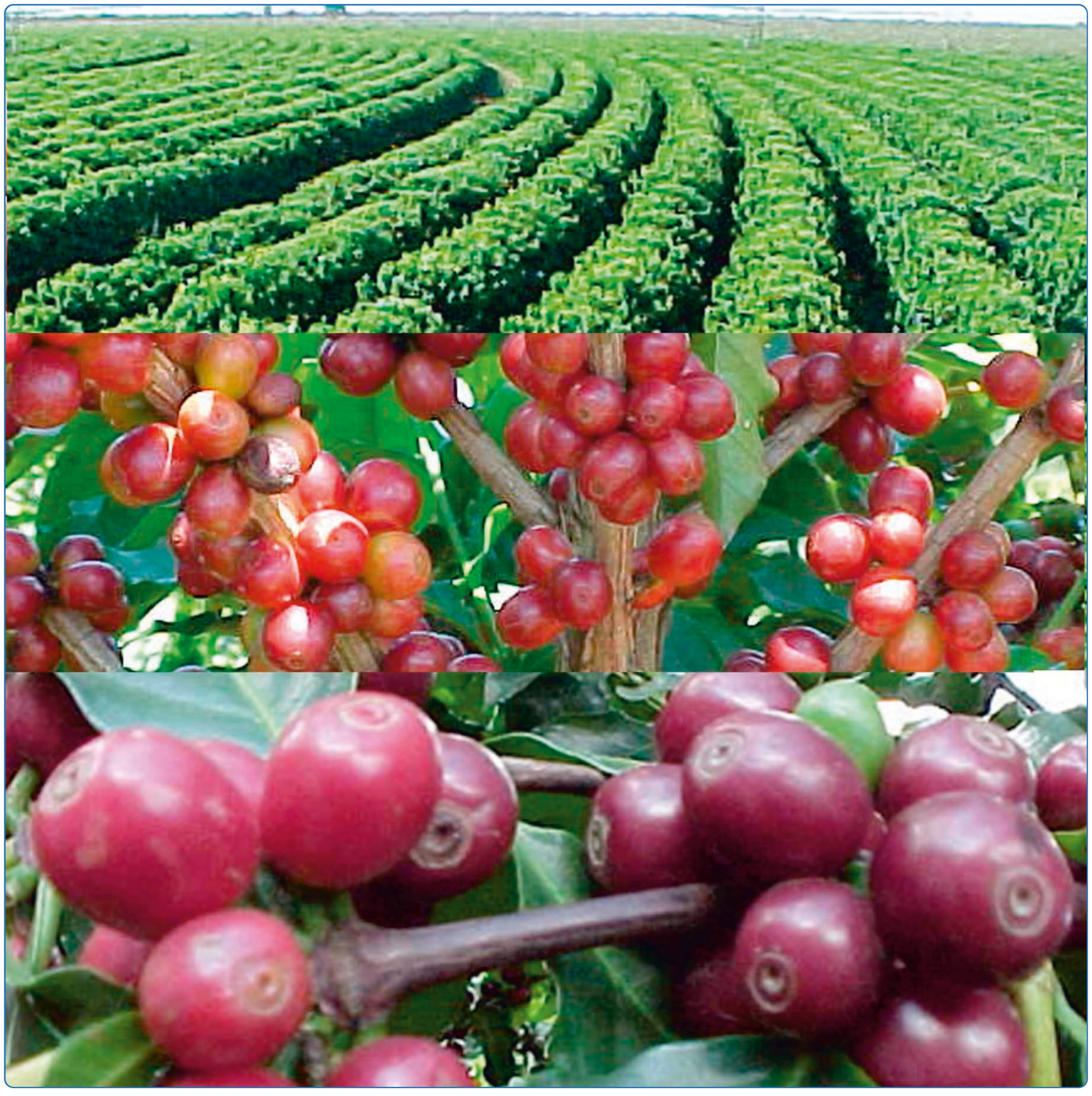

An EST-based analysis identifies new genes and reveals distinctive gene expression features of Coffea arabica and Coffea canephora

Mondego et al.

() Biomed Central 


\title{
An EST-based analysis identifies new genes and reveals distinctive gene expression features of Coffea arabica and Coffea canephora
}

Jorge MC Mondego ${ }^{1 \dagger}$, Ramon O Vidal ${ }^{2,3+}$, Marcelo F Carazzolle ${ }^{2,4}$, Eric K Tokuda ${ }^{2}$, Lucas P Parizzi ${ }^{2}$, Gustavo GL Costa ${ }^{2}$, Luiz FP Pereira ${ }^{5}$, Alan C Andrade ${ }^{6}$, Carlos A Colombo ${ }^{1}$, Luiz GE Vieira ${ }^{7}$, Gonçalo AG Pereira $2^{*}$, for Brazilian Coffee Genome Project Consortium

\begin{abstract}
Background: Coffee is one of the world's most important crops; it is consumed worldwide and plays a significant role in the economy of producing countries. Coffea arabica and C. canephora are responsible for 70 and $30 \%$ of commercial production, respectively. C. arabica is an allotetraploid from a recent hybridization of the diploid species, C. canephora and C. eugenioides. C. arabica has lower genetic diversity and results in a higher quality beverage than C. canephora. Research initiatives have been launched to produce genomic and transcriptomic data about Coffea spp. as a strategy to improve breeding efficiency.

Results: Assembling the expressed sequence tags (ESTs) of C. arabica and C. canephora produced by the Brazilian Coffee Genome Project and the Nestlé-Cornell Consortium revealed 32,007 clusters of C. arabica and 16,665 clusters of C. canephora. We detected different GC3 profiles between these species that are related to their genome structure and mating system. BLAST analysis revealed similarities between coffee and grape (Vitis vinifera) genes. Using KA/KS analysis, we identified coffee genes under purifying and positive selection. Protein domain and gene ontology analyses suggested differences between Coffea spp. data, mainly in relation to complex sugar synthases and nucleotide binding proteins. OrthoMCL was used to identify specific and prevalent coffee protein families when compared to five other plant species. Among the interesting families annotated are new cystatins, glycine-rich proteins and RALF-like peptides. Hierarchical clustering was used to independently group C. arabica and C. canephora expression clusters according to expression data extracted from EST libraries, resulting in the identification of differentially expressed genes. Based on these results, we emphasize gene annotation and discuss plant defenses, abiotic stress and cup quality-related functional categories.

Conclusion: We present the first comprehensive genome-wide transcript profile study of C. arabica and C. canephora, which can be freely assessed by the scientific community at http://www.lge.ibi.unicamp.br/ coffea. Our data reveal the presence of species-specific/prevalent genes in coffee that may help to explain particular characteristics of these two crops. The identification of differentially expressed transcripts offers a starting point for the correlation between gene expression profiles and Coffea spp. developmental traits, providing valuable insights for coffee breeding and biotechnology, especially concerning sugar metabolism and stress tolerance.
\end{abstract}

\footnotetext{
* Correspondence: goncalo@unicamp.br

† Contributed equally

${ }^{2}$ Laboratório de Genômica e Expressão, Departamento de Genética, Evolução

e Bioagentes, Instituto de Biologia, Universidade Estadual de Campinas, CP

6109, 13083-970, Campinas-SP, Brazil

Full list of author information is available at the end of the article
} 


\section{Background}

Coffee is the most important agricultural commodity in the world and is responsible for nearly half of the total exports of tropical products [1]. Indeed, coffee is an important source of income for many developing tropical countries. Brazil, Vietnam and Colombia account for $>50 \%$ of global coffee-production. In addition, coffee is also important to many non-tropical countries that are highly involved in coffee industrialization and commerce and are intensive consumers of coffee beverages.

Two species of the genus Coffea are responsible for almost all coffee bean production: $C$. arabica and $C$. canephora (approximately 70 and $30 \%$ of worldwide production, respectively). $C$. arabica is an autogamous allotetraploid (amphidiploid; $2 n=4 \times=44$ ) species originating from a relatively recent cross ( $\cong 1$ mya) between C. canephora (or a canephoroide-related species) and $C$. eugenioides, which occurred in the plateaus of Central Ethiopia [2,3]. As a consequence of its autogamy and evolutionary history, "Arabica" coffee plants have a narrow genetic basis. This problem is amplified in the main cultivated genotypes (i.e., Mundo Novo, Catuai and Caturra), which were selected from only two base populations: Typica and Bourbon [4]. Conversely, C. canephora is a diploid $(2 \mathrm{n}=2 \times=22)$, allogamous and more polymorphic Coffea species. In contrast to C. arabica, which is grown in highland environments, C. canephora is better adapted to warm and humid equatorial lowlands. C. arabica is regarded as having a better cup quality, which seems to depend on the quality and amount of compounds stored in the seed endosperm during bean maturation [5-7]. Conversely, C. canephora is considered more resistant to diseases and pests and has a higher caffeine content than C. arabica [8]. Other important differences are related to fruit maturation. Though C. canephora blossoms earlier, its fruit maturation is delayed in comparison to C. arabica [9]. Improvements in the agronomic characteristics of coffee (e.g., cup quality, pathogen and insect resistance and drought stress tolerance) are long-sought by the coffee farming-community. However, the introduction of a new trait into an elite coffee variety via conventional breeding techniques is a lengthy process due to the narrow genetic basis of $C$. arabica $[4,10]$ and the long seedto-seed generation cycle.

Expressed sequence tags (ESTs) provide a source for the discovery of new genes and for comparative analyses between organisms. Many EST sequencing efforts have successfully provided insights into crop plants development [11-18]. EST sequencing allows quantitative expression analyses by correlating EST frequency with the desirable traits of plant species. It also constitutes an interesting tool for the detection of tissue/stress specific promoters and genetic variation that may account for specific characteristics. Furthermore, EST analyses can provide targets for transgenesis, an interesting tool for genetic improvement of such a long generation time crop as coffee. In fact, data in coffee genetic transformation indicate the potential of this approach in molecular breeding $[19,20]$.

Research on coffee genomics and transcriptomics has gained increasing attention recently. A Brazilian consortium (Brazilian Coffee Genome Project; BCGP) [21] was developed to investigate coffee traits by sequencing cDNA derived from a series of tissues of $C$. arabica, $C$. canephora and C. racemosa, a coffee species used in breeding programs for the introgression of resistance against coffee leaf miner. Concomitantly, an initiative from the Nestlé Research Center and the Department of Plant Biology at Cornell University sequenced ESTs from $C$. canephora farm-grown in east Java, Indonesia. This research group compared the EST repertoires of $C$. canephora, Solanum lycopersicum (tomato) and Arabidopsis thaliana [22,23]. Based on their analysis, it was verified that $C$. canephora and tomato have a similar assembly of genes, which is in agreement with their similar genome size, chromosome karyotype, and chromosome architecture [22]. In addition, an important platform for functional genomics that can be applied to coffee was carried out by the SOL Genomics Network (SGN; http://sgn.cornell.edu), a genomics information resource for the Solanaceae family and related families in the Asterid clade, such as Coffea spp. and other Rubiaceae species [23].

The availability of EST data from both of the commercially most important Coffea spp. prompted us to perform a wide bioinformatics analysis. In this report, we surveyed the coffee transcriptome by analyzing ESTs from C. arabica and C. canephora. Resources developed in this project provide genetic and genomic tools for Coffea spp. evolution studies and for comparative analyses between $C$. arabica and $C$. canephora, regarding gene families' expansion and gene ontology. We also identified Coffea-specific/prominent gene families using automatic orthology analysis. Additionally, we describe the annotation of differentially expressed genes according to in silico analysis of EST frequencies.

\section{Results and Discussion \\ Overall Coffea spp. EST libraries data}

To evaluate ESTs from Coffea spp. we collected 187,412 ESTs derived from 43 cDNA libraries produced by the Brazilian Coffee Genome Project initiative [21]. The C. arabica libraries represent diverse organs, plant developmental stages and stress treatments from Mundo Novo and Catuaí cultivars, excluding germinating seeds 
(cv Rubi) (Additional File 1). In the case of C. canephora, 62,823 ESTs from six cDNA libraries of the Nestlé and Cornell C. canephora sequencing initiative [22] and 15,647 C. canephora ESTs from three cDNA libraries constructed by the Brazilian Coffee Genome Project initiative [21] were collected yielding a total of 78,470 ESTs (Additional File 1). All ESTs were produced by the Sanger method, and cDNA clones were subjected only to 5 ' sequencing. The pipeline of C. arabica and $C$. canephora EST analysis is described in Figure 1.

After trimming (i.e., vector, ribosomal, short, low quality and $E$. coli contaminant sequences removal), 135,876 C. arabica ESTs were assembled into 17,443 contigs and 17,710 singlets (35,113 clusters; Figure 1), and the $C$. canephora ESTs were assembled into 8,275 contigs and 9,732 singlets (18,007 clusters; Figure 1). After manual annotation, we detected some clusters similar to bacterial sequences that were not identified during trimming. Clusters were then evaluated using BLASTN against a version of NT-bac and BLASTX against the NR database. Sequences similar to bacteria were removed from further analyses. These sequences are likely derived from endophytes of coffee plants. After their removal from the dataset, the final number of clusters was 32,007 (15,656 contigs and 16,351 singlets) from C. arabica and 16,665 (7,710 contigs and 8,955 singlets) from
C. canephora (Table 1). The average length of C. canephora and C. arabica clusters in the dataset was 662 bp (ranging from 100 to 3,584 bp) and $663 \mathrm{bp}$ (ranging from 100 to $2,988 \mathrm{bp}$ ), respectively (Table 1 ). The number of ESTs in the C. canephora and C. arabica contigs ranged from 2 to 1,395 and 2 to 493, respectively (Figure 2). In both cases, approximately $63 \%$ were composed of $\leq 20$ ESTs, and $98 \%$ of the contigs contained < 50 ESTs. We also verified the distribution of ESTs in contigs across multiple libraries. Nineteen percent of C. arabica contigs and $4 \%$ of C. canephora contigs were found in only one library (Additional File 2). The majority of C. arabica contigs (32\%) have only two ESTs, each one from a different EST library. Due to the limited depth of sequencing and the variety of tissue samples used to construct the $C$. arabica libraries, a smoother distribution of contigs per library was observed in comparison with C. canephora (Additional File 2).

\section{Evaluation of GC content, SNPs and sequence similarity with other species}

We evaluated the structure of Coffea contigs to identify the percentage of coding sequences (CDS) in our dataset using the QualitySNP program tools [24]. The mode and median length of CDS and 5' and 3' UTRs were similar to both species (Table 2). We also inspected the

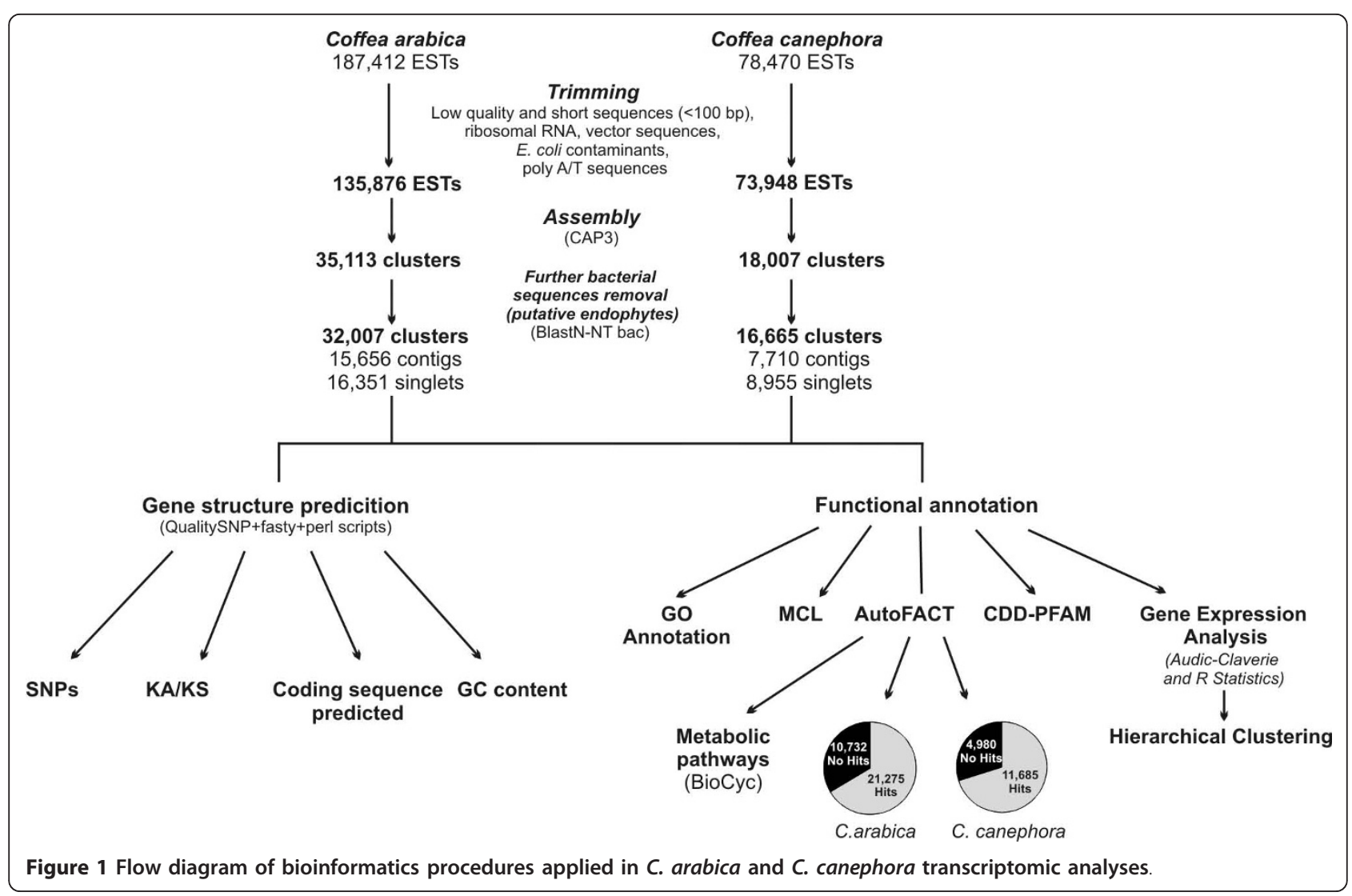


Table 1 Summary of Coffea spp. cluster datasets

\begin{tabular}{ccccccc}
\hline & Contigs & Average contig length & Singlets & Average singlet length & Clusters & Average cluster length \\
\hline C. arabica & 15,656 & $868 \mathrm{bp}$ & 16,351 & $459 \mathrm{bp}$ & 32,007 & $662 \mathrm{bp}$ (ranging from 100 to 3,584 bp) \\
\hline C. canephora & 7,710 & $832 \mathrm{bp}$ & 8,955 & $494 \mathrm{bp}$ & 16,665 & $663 \mathrm{bp}$ (ranging from 100 to 2,988 bp) \\
\hline
\end{tabular}

amount of full length CDS in our dataset, resulting in 1,189 contigs in C. arabica (8\%) and 518 contigs in C. canephora (7\%; Table 2).

Based on the annotation of CDS, we evaluated the GC content in coding regions. In general, the GC and GC3 profiles (i.e., the GC level at the third codon position) of C. canephora and C. arabica are similar to Arabidopsis and tomato. The unimodal GC distribution is a common feature of dicotyledons (Figure 3), whereas bimodal distribution is common in monocotyledons $[17,25]$. Nevertheless, Coffea spp.and Arabidopsis have a slightly higher proportion of genes with high GC content than tomato and have a more accentuated peak shift in GC3 content (Figure 3). This difference between Arabidopsis and tomato was found previously [25] and was attributed to differences in the gene samples, such as the presence of intron-retained transcripts (differentially spliced transcripts) in tomato. A more detailed inspection revealed that $C$. arabica has only one GC3 peak, while C. canephora has two close peaks: the first similar to that found for $C$. arabica and the other positioned toward the "GC-rich content area". This C. canephora pattern may be related to its outcrossing mating system because allogamous species tend to accumulate more polymorphism in the third codon position and to be more GC-rich than autogamous species [26], as is the case of Arabica coffee, tomato and Arabidopsis.

We also used QualitySNP to calculate SNPs present in C. arabica and C. canephora contigs. In the case of C. arabica, we selected contigs containing at least four reads, which in theory provide two copies for each allele,

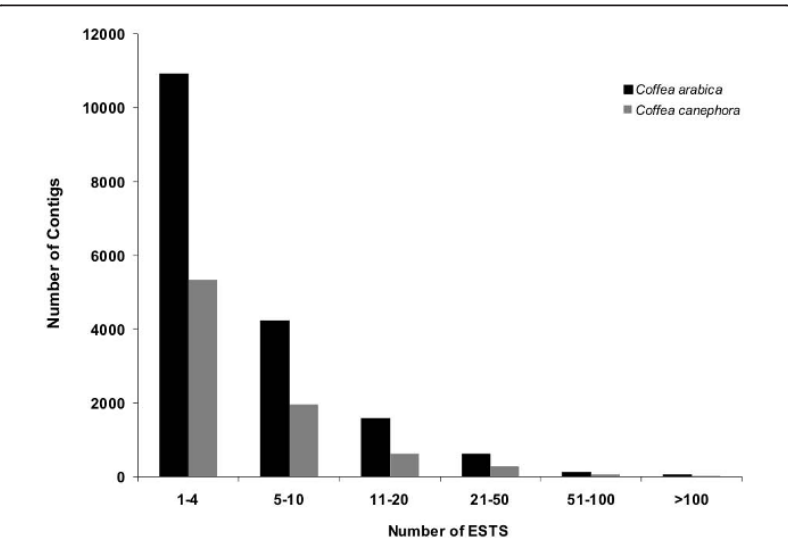

Figure 2 Distribution of the number of ESTs in contigs of C. arabica and C. canephora after the assembly process. yielding 8,514 C. arabica and 3,832 C. canephora contigs. Approximately $53 \%(4,535)$ of the $C$. arabica contigs and $52 \%(2,000)$ of the C. canephora contigs were found to contain SNPs (Additional File 3). Similar to other reports [27-29], more transitions than transversions were found for both species (Additional File 3), likely reflecting the high frequency of cytosine to thymine mutation after methylation. The frequency of SNPs in C. arabica was $0.35 \mathrm{SNP} / 100 \mathrm{bp}$, almost double the C. canephora SNP frequency (0.19 SNP/100 bp). Similarly, Lashermes et al. [3] and Vidal et al. [30] indicated that Arabica has a level of internal genetic variability almost twice that present in C. canephora. The majority of polymorphisms found in both species was bi-allelic $(99.8 \%$ for C. arabica and $99.5 \%$ for C. canephora), with a low percentage of tri-allelic and no tetra-allelic SNPs (Additional File 3)

We next used AutoFACT [31] to evaluate the putative functions of the two Coffea datasets. The results of BLASTX against the non-redundant protein sequence database (NR; E-value cutoff of $1 \mathrm{e}^{-10}$ ) available at AutoFACT were inspected to evaluate the similarity of Coffea clusters with proteins deposited in GenBank. Approximately $68 \%$ of $C$. arabica and $71 \%$ of C. canephora clusters have significant sequence similarity $\left(E-v a l u e ~ \leq 1 e^{-10}\right)$ with genes in the databank. The remaining clusters represented sequences with lower E-value scores (E-value $>1 \mathrm{e}^{-10}$ ) designated as "no-hits" (Table 3). Because C. arabica and C. canephora are species from the Rubiaceae family, which have few sequences deposited in the NR database, we expected that sequences from other species in the Asteridae clade (e.g., members of the Solanaceae family S. lycopersicum, S. tuberosum and Nicotiana tabacum) would be the most similar to Coffea sequences. However, the majority of Coffea clusters have higher similarity with Vitis vinifera sequences $(\sim 40 \%)$, a species from the Rosids clade, followed by the other rosids Arabidopsis $(\sim 5.5 \%)$ and Populus trichocarpa ( 3.5\%). The top hits of Coffee sequences with Solanaceae range from 1 to $2 \%$ (Table 3). We then compared the Coffea sequences with a database containing contigs from the plant EST databank TIGR, the plant transcript database http://plantta.jcvi.org and GeneIndex Plants http://compbio.dfci.harvard.edu/tgi/plant.html, which have a higher amount of Solanaceae data. For both C. arabica and C. canephora, N. tabacum was the species with more top hits (11.15 and $11.59 \%$, respectively), followed by $V$. vinifera (10.34 and 10.03\%), S. lycopersicum (6.5 and 5\%) and S. tuberosum (5 and 4.8\%; data not 
Table 2 Evaluation of CDS, 5'UTR and 3'UTR of Coffea spp

\begin{tabular}{lccccc}
\hline & Full length CDS sequences & 5'UTR length (median) & CDS length (median) & CDS length (mode) & 3'UTR length (median) \\
\hline C. arabica & 1,189 & $160 \mathrm{bp}$ & $836 \mathrm{bp}$ & $479 \mathrm{bp}$ & $240 \mathrm{bp}$ \\
\hline C. canephora & 518 & $134 \mathrm{bp}$ & $708.5 \mathrm{bp}$ & $476 \mathrm{bp}$ & $229.5 \mathrm{bp}$ \\
\hline
\end{tabular}

shown). We believe that the most parsimonious hypothesis for these results is related to phylogenetic issues. Grape is basal to the rosids clade and did not undergo whole genome duplication (WGD) events, such as Arabidopsis, thus being theoretically more similar to the rosids paleohexaploid ancestor [32,33]. Analysis of genomic sequences from the asterid common monkey flower (Mimulus guttatus) revealed extensive synteny with grape, suggesting that paleohexaploidy antedates the divergence of the rosid and asterid clades [33]. Notably, recent data prove that there is a high level of collinearity between diploid Coffea and $V$. vinifera genomic regions [34], and that these species derive from the same paleohexaploid ancestral genome [35]. Intensive genomic analyses are currently underway to more deeply compare the genomes of rosids and asterids species.

To gain insight into the molecular evolution of protein coding genes in the two Coffea species analyzed, we estimated the rates of synonymous (KS, silent mutation)

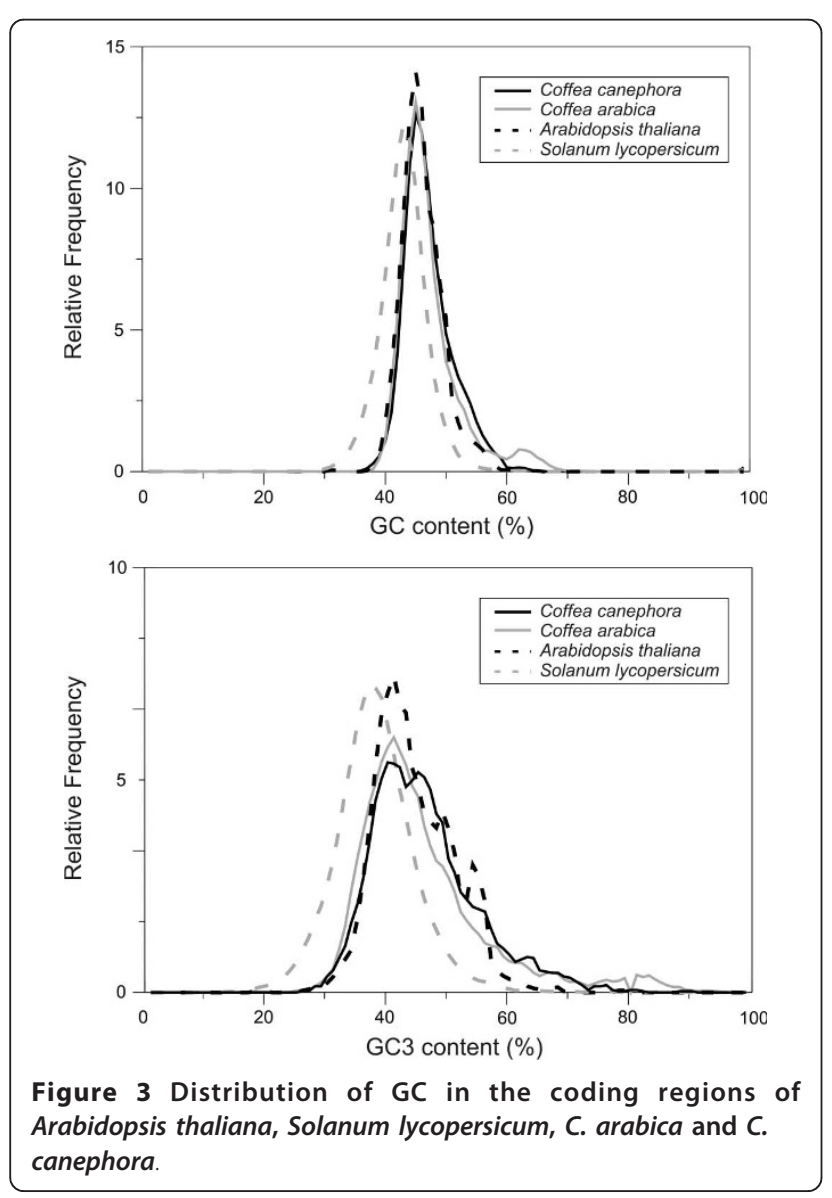

and non-synonymous (KA, amino-acid altering mutation) substitutions generated by QualitySNP analysis, and performed the KA/KS test for positive selection of each hypothetical gene. KA/KS is a good indicator of selective pressure at the sequence level. Theoretically, a $\mathrm{KA} / \mathrm{KS}>1$ indicates that the rate of evolution is higher than the neutral rate. Conversely, a gene with $\mathrm{KA} / \mathrm{KS}<$ 1 has a rate of evolution less than the neutral rate [36]. As in other plant species [37,38], most genes in C. arabica and C. canephora appear to be under purifying selection $(\mathrm{KA} / \mathrm{KS}<1)$, indicating that the majority of protein-coding genes are conserved over time as a result of selection against deleterious variants.

Table 3 Predicted C. arabica and C. canephora gene comparisons

\begin{tabular}{lrr}
\hline Coffea arabica & & \\
\hline Species & \# Hits* & $\%$ Hits \\
\hline Vitis vinifera & 13,855 & $43.29 \%$ \\
Arabidopsis thaliana & 1,846 & $5.77 \%$ \\
Populus trichocarpa & 1,161 & $3.63 \%$ \\
Oryza sativa & 643 & $2.01 \%$ \\
Nicotiana tabacum & 641 & $2.00 \%$ \\
Solanum tuberosum & 428 & $1.34 \%$ \\
Solanum lycopersicum & 392 & $1.22 \%$ \\
Medicago truncatula & 149 & $0.47 \%$ \\
Catharanthus roseus & 115 & $0.36 \%$ \\
Glycine max & 104 & $0.32 \%$ \\
Others & 1,941 & $6.06 \%$ \\
No hits & 10,732 & $31.66 \%$ \\
\hline Coffea canephora & & \\
\hline Species & $\#$ Hits & $\%$ Hits \\
\hline Vitis vinifera & 7,427 & $44.57 \%$ \\
Arabidopsis thaliana & 972 & $5.83 \%$ \\
Populus trichocarpa & 639 & $3.83 \%$ \\
Oryza sativa & 372 & $2.23 \%$ \\
Nicotiana tabacum & 362 & $2.17 \%$ \\
Solanum tuberosum & 232 & $1.39 \%$ \\
Solanum lycopersicum & 225 & $1.35 \%$ \\
Medicago truncatula & 105 & $0.63 \%$ \\
Solanum demissum & 64 & $0.37 \%$ \\
Catharanthus roseus & 56,980 & $0.32 \%$ \\
Others & $7.39 \%$ \\
No hits & $29.88 \%$ \\
\hline Each coffe clister & \\
\hline
\end{tabular}

*Each coffee cluster was compared to all of the proteins from the organisms listed. The BLASTX score was defined as $1 \mathrm{e}^{-10}$. 
The correlation between AutoFACT annotations with $\mathrm{KA} / \mathrm{KS}$ analysis allowed the detection of genes with low $\mathrm{KA} / \mathrm{KS}$ ratios, such as those encoding proteins involved in photosynthesis, morphogenetic development and translation (Additional File 4). The majority of these proteins have been shown to be highly conserved and to suffer strong purifying selection [37]. Analyzing the genes with the highest $\mathrm{KA} / \mathrm{KS}$, we identified effector proteins and transcription factors related to biotic and abiotic stress and proteins involved in oxidative respiration (Additional File 4). These results are in accordance with previous reports, which show that genes acting in response to stress are often positively selected for diversification due to the competition with the evolving effector proteins of pathogens $[37,39]$.

\section{Metabolic Pathways}

We constructed hypothetical metabolic maps for both C. arabica and C. canephora using BioCyc [40]. After manual annotation, 345 pathways in C. arabica and 300 pathways in C. canephora were detected. C. arabica pathways included 3,366 enzymes in 1,807 enzymatic reactions. In the case of C. canephora, 1,889 enzymes were present in 1,653 enzymatic reactions. The almost twofold difference in the number of enzymes between the two coffee species is related to the number of ESTs annotated for each species. Therefore, assigning the presence/ absence of a pathway in one Coffea species relative to the other should be done carefully. Further, the number of $C$. arabica enzymatic reactions may be underestimated due to duplicated genes in C. arabica, each one most likely derived from a different ancestor (C. canephora and C. eugenioides), because that two enzymatic reactions in C. arabica may be annotated as only one. The data for the fully annotated pathways are available at the website http://www.lge.ibi.unicamp.br/coffea.

\section{Protein Domains}

We performed a comparison of C. arabica and C. canephora gene clusters with the CDD-PFAM databank to catalog the protein domains present in the Coffea EST datasets. The submission of the clusters to RPS-BLAST resulted in $30 \%(9,886)$ of $C$. arabica and $32 \%(5,478)$ of C. canephora clusters containing an assigned domain. To compare the prevalence of protein domains in Coffea species, the number of clusters assigned to each domain was normalized by dividing by the total number of clusters containing a domain. Serine threonine kinases (Pfam00069), cytochrome P450 monooxygenases (Pfam00067), tyrosine kinases (Pfam07714) and proteins containing RNA recognition motifs (RRM; Pfam00076) are among the top 20 PFAM families in Coffea species (Additional File 5). Next, we plotted the percentage of protein domains in Coffea datasets in a comparative histogram. Protein domain analysis revealed significant differences between the two species datasets (Figure 4). For example, C. arabica contains more cytochrome P450 monooxygenases, tyrosine kinases, extensin-like proteins, glycine-rich proteins, sugar transporters, UDP glucosyltransferases, NAD-dependent epimerases, DNA-J proteins, NB-ARC proteins, cellulose synthases, raffinose synthases, D-mannose-binding lectins and flavin amine oxidoreductases than C. canephora (Figure 4). In contrast, the $C$. canephora dataset contains a higher percentage of transcripts coding for proteins containing RRM motifs, ubiquitin conjugation enzymes, ABC transporters, Ras/Rab/Rac proteins, 2-OG oxygenases, cupin proteins, HSP20 s, HSP70 s, ADP-ribosylation factors, dehydrins, glutenins and seed maturation proteins (Figure 4). Despite these dissimilarities between datasets may be caused by the different tissues used for constructing the C. arabica and C. canephora cDNA libraries, such results offer clues for further comparative research.

One noteworthy difference between domains is the greater percentage of proteins containing the retrotransposon gag protein domain (Pfam03732) in C. canephora $(0.26 \%)$ than in C. arabica $(0.02 \%)$. This domain is found in LTR-retrotransposons, the most widespread transposable element (TE) family in plants [41]. Lopes et al. [42] found that Coffea species harbor fewer TE-cassettes $(>0.04 \%)$ than would be expected from the translation of TE-containing transcripts (0.23\%). These authors hypothesized that such incongruence may either be a consequence of the exonization/exaptation of TE fragments or an indication of the tolerance of alternatively spliced "TE-invaded" mRNAs that do not encode functional proteins. A more detailed investigation is in progress to explore the diversity and differences between Coffea spp. TEs (F.R. Lopes, M.F. Carazzolle, G.A.G. Pereira, C.A. Colombo, C.M.A. Carareto; unpublished data).

\section{Gene Ontology Analysis and Annotation}

A functional annotation was performed by mapping contigs assembling onto gene ontology (GO) structures [43]. Approximately 38\% of C. arabica and 49\% of C. canephora clusters were mapped with a biological process, and 43 and 55\% were mapped with a molecular function. These differences reflect the greater amount of C. arabica ESTs in the libraries compared to C. canephora and are likely related to the fact that some tissues used in C. arabica libraries (i.e., callus) were not extensively studied, resulting in genes with unassigned ontologies. To compare the gene ontologies, the amount of sequences associated with each term was normalized (see methods), and then hypergeometric statistics were applied [44]. To compare GO data with our other protein-related analysis, we focused our evaluation on 


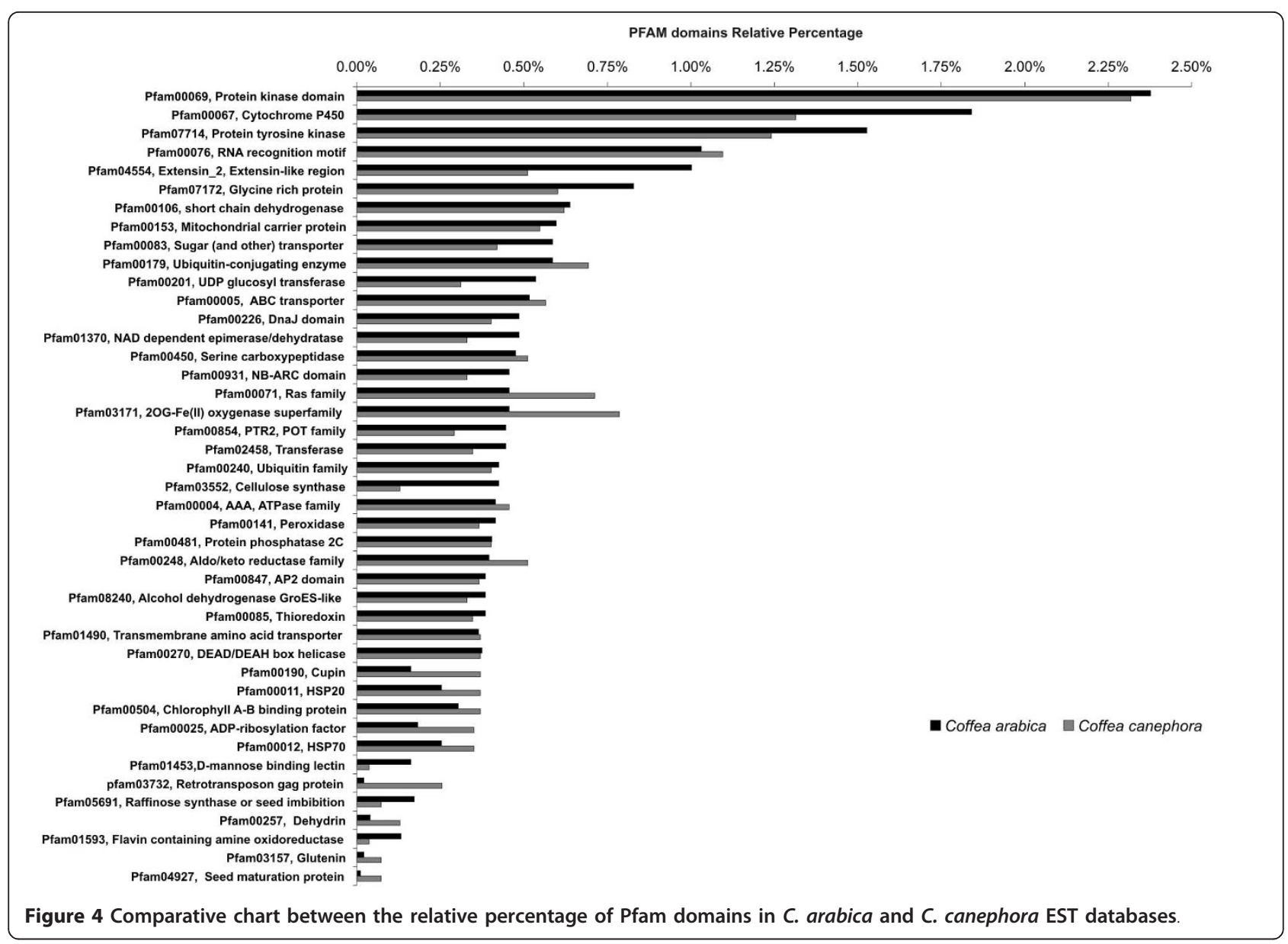

molecular activity ontology. We observed that $C$. arabica has a greater amount of transcripts coding for proteins with catalytic activity, transferase activity and transporter activity than C. canephora (Figure 5). In accordance, the CDD-PFAM analyses showed that $C$. arabica had a greater percentage of cellulose synthases, raffinose synthases, UDP-glucuronosyl transferases, secondary metabolism-related transferases, ABC transporters and sugar transporters (Figure 4; Additional File 5). The evidence that transcripts coding for proteins related to sugar metabolism and transport are more prevalent in $C$. arabica than in C. canephora may be related to the high content of sugars (especially sucrose) in fruits of Arabica plants, one of the traits that provides a better cup quality (see below). In contrast to C. arabica, $C$. canephora has more proteins annotated as containing binding activity, which is extended for the binding activity branch child terms of nucleic acid binding, DNA and RNA binding activities, transcription regulation and transcription factor activities (Figure 5). These data are also in agreement with our domain analysis (Figure 4; Additional File 5), indicating a higher percentage of Ras/ $\mathrm{Rac} / \mathrm{Rab}$ GTPase proteins, including regulators of vesicle biogenesis in intracellular traffic, ADP-ribosylation factors and proteins containing RRM and G-patch motifs, involved in RNA binding activity [45].

\section{Orthologous Family Clustering: Searching for Coffee- Specific Families}

To identify proteins that are hypothetically specific or at least prominent in Coffea spp. in comparison to other

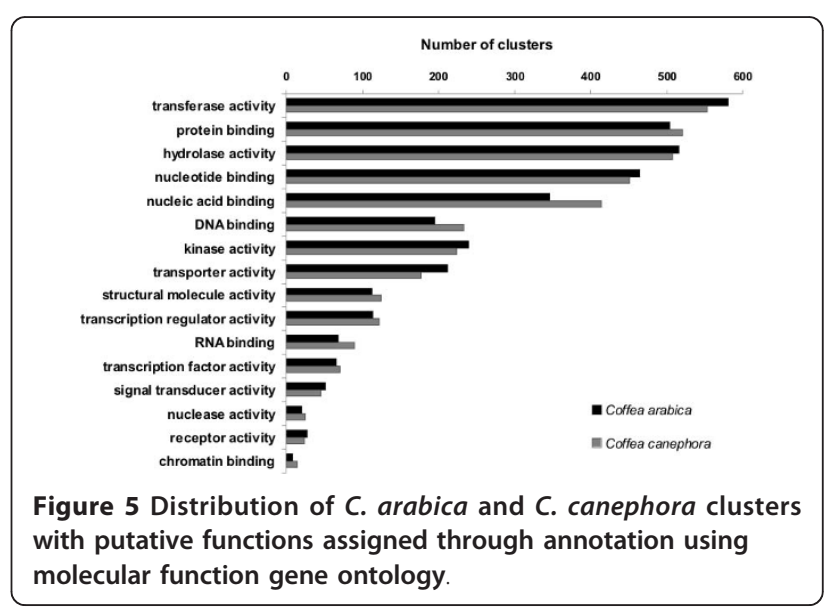


species, we applied OrthoMCL, a graph-clustering algorithm designed to identify homologous proteins based on sequence similarity $[46,47]$. Two different types of datasets were used in this analysis: i) the annotated proteins from the available complete genomes of $A$. thaliana, $V$. vinifera, Oryza sativa, Ricinus communis and Glycine max and ii) the proteins predicted by FrameDP software [48] from the available ESTs assemblies for $C$. arabica, C. canephora and S. lycopersicum. Based on the fact that some genes are not picked in EST libraries, the evaluation of Coffea spp. gene family retraction was not performed (i.e., the absence of a gene does not mean that it is not present in the genome but rather that it is expressed in a minor amount).

We identified 24,577 different families using the eight aforementioned species. The majority of families were ubiquitous, being present in all analyzed species. The top three OrthoMCL families in Coffea spp. are: i) a family composed of serine/threonine kinases (family 1), ii) pentatricopeptide repeat-containing proteins (family 2) and iii) cytochrome P450 monooxygenases (family 6; Table 4). The analysis was focused on the annotation of families that appeared to be specific from Coffea species or that are prominent in those EST datasets. In C. arabica, we highlight family 544, which contains proteins similar to the cysteine proteinase inhibitors cystatins. This family includes 21 members in C. arabica, six in $C$. canephora and only one member in the grape genome (Table 4). Two other proteins families composed of cystatin-like proteins (families 2703 and 11594) are also prominent in coffee plants. Other protein families that appear to be prominent/specific in C. arabica include small secreted glycine-rich proteins similar to Panax ginseng [49] (families 1231, 4031 and 11588), NBS-LRR resistance proteins (families 453, 3289 and 2722), Pin2like serine proteinase inhibitors (families 7241 and 10273), conserved proteins of unknown function (families 10956, 11617, 12384, 12386, 11626 and 13353), proteins not previously described (no hits; families 14110 and 14413), etc. (Table 4). In C. canephora, the "species-specific/prominent" gene families include those encoding miraculin-like proteins (family 14813), C. canephora-specific invertase inhibitors (family 14814), small secreted glycine-rich proteins (family 11055), Ty3 Gypsy-like retrotransposons (family 10952), kelch repeat phosphatases (family 14392), $2 \mathrm{~S}$ albumin storage proteins (family 14392), etc. (Table 4). Five families are specific or prominent in both $C$. arabica and C. canephora when compared to the other species analyzed. Two of these contain proteins not previously described (no hits, families 10281 and 12375). The other three include proteins similar to rapid alkalinization factor (RALF, family 8498), GTP binding proteins (family 9023) and prolinerich extensins (family 12371; Table 4).

\section{In silico Evaluation of Gene Expression in C. arabica and C. canephora}

We correlated the AutoFACT annotation results with the distribution of contigs in the C. arabica and $C$. canephora libraries (Additional Files 6 and 7). The majority of the most widely distributed genes is related to RNA processing, translation, protein turnover and protein folding. This was an expected result because these biological processes are ubiquitous and indispensable for cellular homeostasis (Additional File 6). In Arabica, the most widely expressed contigs encode a papain-like cysteine (cys) proteinase (234 ESTs) and a polyubiquitin (207 ESTs), each one distributed among 30 libraries, followed by glyceraldehyde 3-phosphate dehydrogenase (GAPDH; 162 ESTs) and a heme-containing peroxidase (245 ESTs), both distributed among 29 libraries (Additional File 6). Both polyubiquitin and GAPDH were previously tested as suitable reference genes for qPCR expression analysis in C. Arabica [50-52], which reinforces the accuracy of our bioinformatics analyses. The data presented here provide additional genes to be tested for normalization of qPCR, an essential procedure to avoid misinterpretation when measuring gene expression [53]. The lack of libraries from diverse tissues does not allow reliable inferences about the ubiquity of genes in C. canephora. However, the most widely expressed contig (22 ESTs in nine libraries) encodes a putative VTC2 protein, a GDP-Dglucose phosphorylase involved in ascorbic acid biosynthesis [54], suggesting the synthesis of ascorbate throughout fruit development in C. canephora, which is likely used as an antioxidant and as a cofactor for dioxygenases.

The evaluation of the contigs distribution in Coffea libraries also revealed the contigs containing the most redundant (most highly expressed) ESTs (Additional File 7). In C. arabica, a contig encoding a RuBisCo small subunit was found to be the most highly expressed gene, followed by a contig encoding a putative class III chitinase (Additional File 7). Among the top 20 most expressed ESTs are genes involved in detoxification and reactive oxygen species (ROS) tolerance and genes related to biotic and abiotic stress. These annotations may be biased by the significant amount of ESTs derived from biotic or abiotic stressed tissues (Additional File 1). Two genes encoding seed storage proteins ( $2 \mathrm{~S}$ albumin and $11 \mathrm{~S}$ globulin) were the most highly expressed genes in the $C$. canephora dataset, a result similar to that described by Lin et al. [22] (Additional File 7). The use of regulatory elements of these highly expressed genes may be an excellent tool for conferring strong expression to a target gene in transgenesis approaches.

To identify genes uniquely or preferentially expressed in specific coffee EST libraries, R statistics [55] and 
Table 4 OrthoMCL analysis of C. arabica and C. canephora, highlighting prominent and specific families in Coffea spp

\begin{tabular}{|c|c|c|c|c|c|c|c|c|c|}
\hline $\begin{array}{l}\text { OrthoMCL } \\
\text { family ID }\end{array}$ & $\begin{array}{c}\text { Coffea } \\
\text { arabica }\end{array}$ & $\begin{array}{c}\text { Coffea } \\
\text { canephora }\end{array}$ & $\begin{array}{c}\text { Vitis } \\
\text { Vinifera }\end{array}$ & $\begin{array}{c}\text { Solanum } \\
\text { lycopersicum }\end{array}$ & $\begin{array}{l}\text { Glycine } \\
\max \end{array}$ & $\begin{array}{l}\text { Ricinus } \\
\text { communis }\end{array}$ & $\begin{array}{l}\text { Oryza } \\
\text { sativa }\end{array}$ & $\begin{array}{l}\text { Arabidopsis } \\
\text { thaliana }\end{array}$ & Manual Annotation* \\
\hline 1 & 446 & 189 & 1402 & 808 & 2532 & 1378 & 813 & 847 & Serine-threonine kinase \\
\hline 2 & 152 & 51 & 580 & 212 & 967 & 461 & 478 & 447 & PPR repeat protein \\
\hline 6 & 84 & 41 & 193 & 123 & 226 & 99 & 101 & 108 & Cytochrome P450 \\
\hline 544 & 21 & 6 & 1 & - & - & - & - & - & Cystatin \\
\hline 453 & 14 & 4 & 1 & 7 & 3 & 1 & 1 & 1 & NBS LRR resistance protein \\
\hline 1231 & 13 & 5 & - & - & - & - & - & - & Small secreted glycine-rich protein \\
\hline 4031 & 10 & - & - & - & - & - & - & - & Glycine-rich protein \\
\hline 1510 & 7 & 1 & 1 & - & 2 & 1 & 1 & 3 & UDP-glucosyltransferase \\
\hline 2703 & 6 & 3 & - & 1 & 1 & - & 1 & - & $\begin{array}{c}\text { Cysteine proteinase inhibitor like } \\
\text { protein }\end{array}$ \\
\hline 3289 & 6 & - & 1 & - & 2 & - & 2 & - & NBS LRR resistance protein \\
\hline 5056 & 6 & 1 & - & 1 & - & - & - & - & Alcohol dehydrogenase \\
\hline 2306 & 5 & 1 & - & 2 & 1 & 1 & 2 & - & Cytochrome P450 \\
\hline 2722 & 5 & 1 & - & 1 & 1 & 2 & 1 & 1 & NBS LRR resistance protein \\
\hline 3294 & 5 & - & 1 & - & 3 & - & 1 & 1 & Poly-A binding protein \\
\hline 3303 & 5 & 1 & 2 & 1 & - & - & - & 1 & $\begin{array}{l}\text { NADPH-dependent cinnamyl } \\
\text { alcohol dehydrogenase }\end{array}$ \\
\hline 3305 & 5 & 2 & 1 & 2 & - & - & - & - & Specific tissue protein 2 \\
\hline 4049 & 5 & 2 & 1 & 1 & - & - & 1 & - & Sugar transport protein \\
\hline 4070 & 5 & - & 1 & 1 & 3 & - & - & - & Cytochrome P450 \\
\hline 7241 & 5 & 1 & 1 & - & - & - & 1 & - & $\begin{array}{l}\text { Potato type II serine proteinase } \\
\text { inhibitor family }\end{array}$ \\
\hline 10956 & 5 & - & - & - & - & - & - & - & Hypothetical protein \\
\hline 7610 & 4 & 1 & - & 1 & - & - & - & 1 & Ubiquitin-conjugating enzyme \\
\hline 7611 & 4 & 1 & - & 1 & 1 & - & - & - & P-glycoprotein $A B C$ \\
\hline 7613 & 4 & - & - & 2 & 1 & - & - & - & Hexose transporter \\
\hline 9014 & 4 & 1 & - & - & - & 1 & - & - & $\begin{array}{l}\text { GH3 family protein/Indole-3-acetic } \\
\text { acid-amido synthetase }\end{array}$ \\
\hline 10273 & 4 & 1 & - & - & - & - & - & - & $\begin{array}{l}\text { Potato type II serine proteinase } \\
\text { inhibitor family }\end{array}$ \\
\hline 11588 & 4 & - & - & - & - & - & - & - & Small secreted glycine-rich protein \\
\hline 11617 & 4 & - & - & - & - & - & - & - & Hypothetical protein \\
\hline 12384 & 4 & - & - & - & - & - & - & - & Hypothetical protein \\
\hline 12385 & 4 & - & - & - & - & - & - & - & Defensin/gamma thionin \\
\hline 12386 & 4 & - & - & - & - & - & - & - & Hypothetical protein \\
\hline 7324 & 3 & 2 & - & - & 2 & - & - & - & $\begin{array}{l}\text { Helix-loop-helix DNA-binding } \\
\text { protein }\end{array}$ \\
\hline 9019 & 3 & - & - & 1 & - & 1 & - & - & Zinc/iron transporter \\
\hline 9830 & 3 & - & 3 & - & - & - & - & - & $\begin{array}{c}\text { Eukaryotic initiation factor (elF1)/ } \\
\text { SU1 }\end{array}$ \\
\hline 10271 & 3 & 1 & - & - & - & - & 1 & - & Metallothionein \\
\hline 10276 & 3 & - & - & - & - & 1 & - & 1 & $\begin{array}{l}\text { SEC14 cytosolic factor family } \\
\text { protein }\end{array}$ \\
\hline 10293 & 3 & - & - & 1 & 1 & - & - & - & $A B C$ transporter \\
\hline 10300 & 3 & 1 & - & - & 1 & - & - & - & Phytochrome B/histidine kinase \\
\hline 10309 & 3 & 1 & - & 1 & - & - & - & - & Oxidoreductase \\
\hline 11058 & 3 & - & 1 & 1 & - & - & - & - & ATP-binding cassette transporter \\
\hline 11594 & 3 & - & - & - & - & - & - & 1 & A. thaliana-related cystatin \\
\hline
\end{tabular}


Table 4 OrthoMCL analysis of C. arabica and C. canephora, highlighting prominent and specific families in Coffea spp (Continued)

\begin{tabular}{|c|c|c|c|c|c|c|c|c|c|}
\hline 11600 & 3 & - & - & - & - & - & 1 & - & Alcohol dehydrogenase \\
\hline 11607 & 3 & 1 & - & - & - & - & - & - & CAAX amino-terminal protease \\
\hline 11626 & 3 & 1 & - & - & - & - & - & - & Hypothetical protein \\
\hline 13353 & 3 & - & - & - & - & - & - & - & Hypothetical protein \\
\hline 13392 & 3 & - & - & - & - & - & - & - & GDP-D-mannose 4,6-dehydratase \\
\hline 14410 & 3 & - & - & - & - & - & - & - & No hits found \\
\hline 14413 & 3 & - & - & - & - & - & - & - & No hits found \\
\hline 14414 & 3 & - & - & - & - & - & - & - & $\begin{array}{l}\text { Aspartate aminotransferase } \\
\text { superfamily protein }\end{array}$ \\
\hline 14418 & 3 & - & - & - & - & - & - & - & HAT transposase element \\
\hline 14420 & 3 & - & - & - & - & - & - & - & Protein translation factor SUI1 \\
\hline 8498 & 2 & 5 & - & - & - & - & - & & $\begin{array}{l}\text { Rapid Alkalinization Factor (RALF)- } \\
\text { like protein }\end{array}$ \\
\hline 9023 & 2 & 3 & - & - & - & 1 & - & - & GTP binding protein \\
\hline 10281 & 2 & 3 & - & - & - & - & - & - & No hits found \\
\hline 12371 & 2 & 2 & - & - & - & - & - & 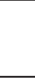 & $\begin{array}{l}\text { Hydroxyproline-rich glycoprotein/ } \\
\text { extension }\end{array}$ \\
\hline 12375 & 2 & 2 & - & & - & - & - & - & No hits found \\
\hline 1715 & - & 4 & 1 & 2 & 1 & 8 & - & - & Viroid polyprotein ORF4 protein \\
\hline 6375 & - & 4 & 2 & 1 & 1 & - & - & - & NBS LRR resistance protein \\
\hline 9679 & - & 3 & 1 & - & 1 & 1 & - & - & Replication factor A 1 \\
\hline 10952 & - & 3 & 1 & - & - & 1 & - & - & LTR retrotransposon \\
\hline 11055 & - & 5 & - & - & - & - & - & - & Small glycine-rich protein \\
\hline 14392 & - & 3 & - & - & - & - & - & - & $\begin{array}{l}\text { Kelch repeat-containing } \\
\text { phosphatase }\end{array}$ \\
\hline 14397 & - & 3 & - & - & - & - & - & - & $\begin{array}{l}\text { Albumin/sulfur-rich seed storage } \\
\text { protein }\end{array}$ \\
\hline 14809 & - & 3 & - & - & - & - & - & - & Hypothetical protein \\
\hline 14813 & - & 3 & - & - & - & - & - & - & Miraculin-like protein \\
\hline 14814 & - & 3 & - & - & - & - & - & - & Invertase inhibitor \\
\hline
\end{tabular}

*Annotation based on BLASTX-NR (E-value $1 \mathrm{e}^{-5}$ ).

Audic Claverie (AC) statistics [56] were used through IDEG6, a web tool for the statistical analysis of gene expression data [57]. Libraries containing < 300 ESTs were discarded from these analyses, because libraries with a small amount of ESTs tend to disturb the prediction of differentially expressed genes. After some manual clusterization, we observed that several libraries derived from the same tissues (EA1, IA1 and IA2; EM1 and SI3; LV4, LV5, LV8 and LV9; FB1 and FB4; and FR1 and FR2) present the same set of genes differentially expressed in comparison to the other libraries. Thus, they were combined for further analyses. After evaluating statistical data, the merging of $\mathrm{AC}$ and $\mathrm{R}$ statistical analyses resulted in 331 contigs from C. arabica and 443 contigs from $C$. canephora. Thereafter, hierarchical clustering was applied to this data using a correlation matrix constructed from EST frequencies for differentially expressed
C. arabica and C. canephora contigs (Figure 6; Additional File 8 ). The clustering results indicated that the differences among C. canephora libraries were more evident than in $C$. arabica, likely due to the small number of libraries of the former (Figure 6A and 6B).

The libraries were manually separated into two groups: "development" libraries, derived from tissues that did not suffer stress; and "stress" libraries that were constructed using RNA from plants challenged with biotic or abiotic stress-triggering factors. This expression "fingerprinting" provides a guideline for the isolation of promoters that regulate expression in specific tissues or stress conditions. Brandalise et al. [58] applied a similar strategy in the isolation of a C. arabica promoter that drives stress-responsive expression in leaves. Some genes with agronomical importance or with interesting expression profiles depicted in Figure 6 are discussed in 
a)

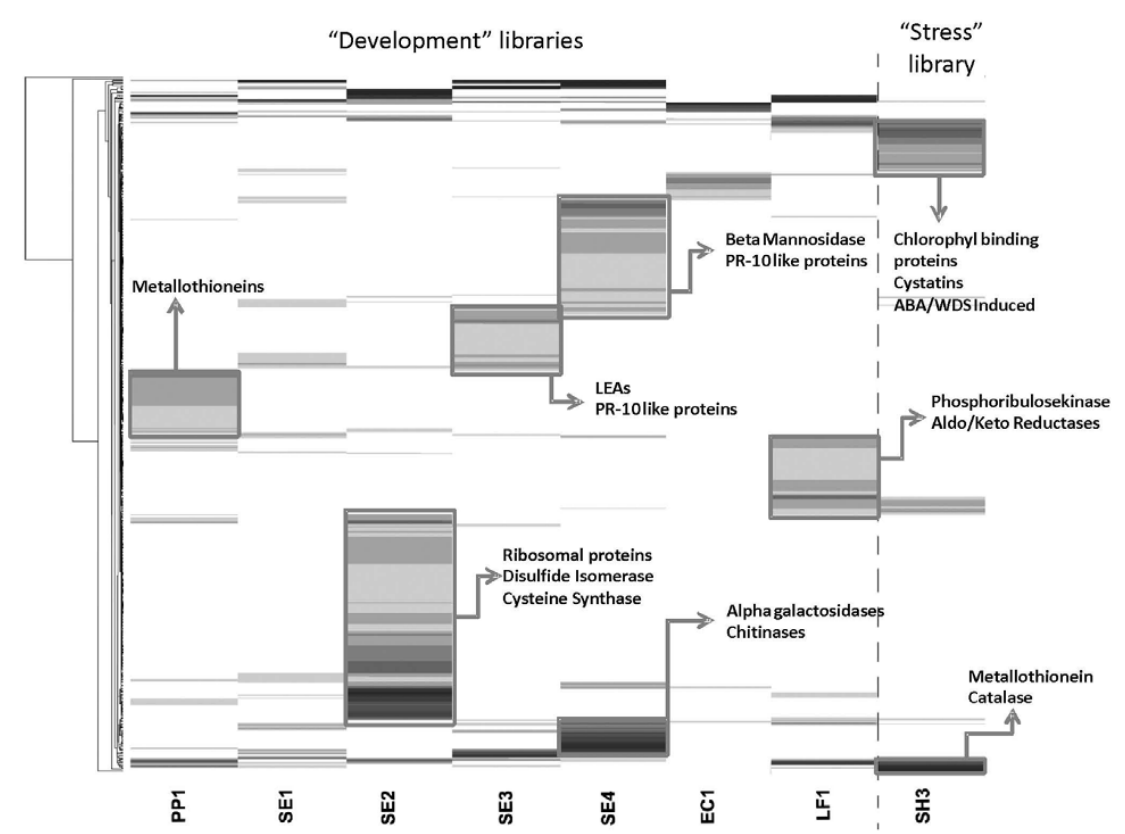

b)

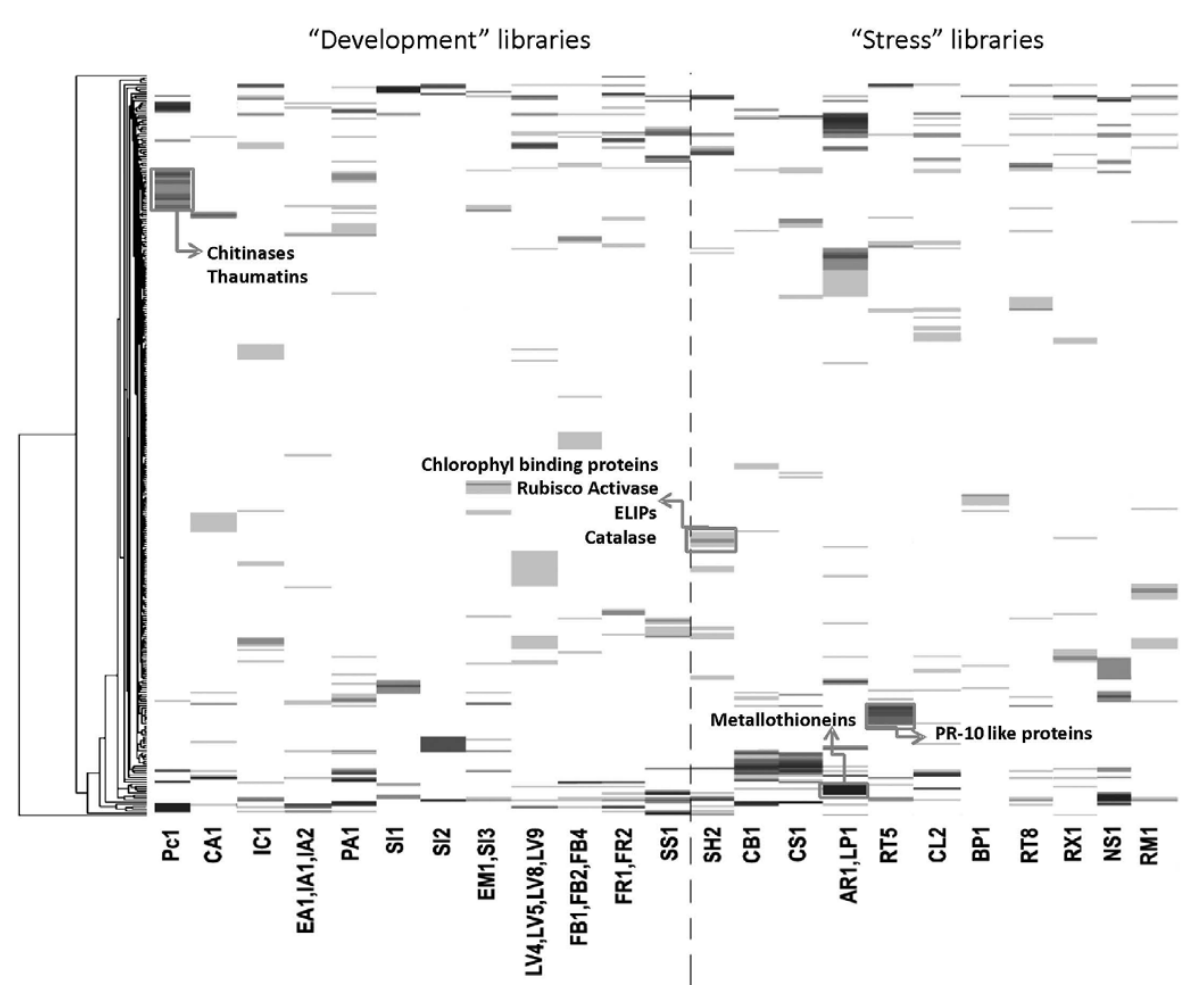

Figure 6 Hierarchical clustering of coffee cDNA libraries and clusters based on EST distribution. a) C. canephora hierarchical clustering of 443 clusters differentially expressed vs. the eight CDNA library assemblies. b) C. arabica hierarchical clustering of 331 clusters differentially expressed vs. the 23 cDNA library assemblies. Hierarchical clustering was performed using a correlation matrix constructed from EST frequencies for differentially expressed C. arabica and C. canephora contigs. Black intensity designates relative transcript abundance in a given library, as inferred from EST frequency within each contig. Library abbreviations correspond to the following descriptions: C. canephora: LF; young leaves, PP1; pericarp, all developmental stages; SE1; whole cherries, 18 and 22 weeks after pollination; SE2, whole cherries,18 and 22 weeks after pollination; SE3: endosperm and perisperm, 30 weeks after pollination SE4; endosperm and perisperm, 42 and 46 weeks after pollination; EC1: embriogenic calli; SH1: leaves from water deficit stressed plants; and SH3: leaves from water deficit stressed plants (drought resistant clone). C. arabica: PC1, C. arabica non-embryogenic cell line induced with 2,4-D; CA1, non-embryogenic calli; IC1, C. arabica non-embryogenic cell line 


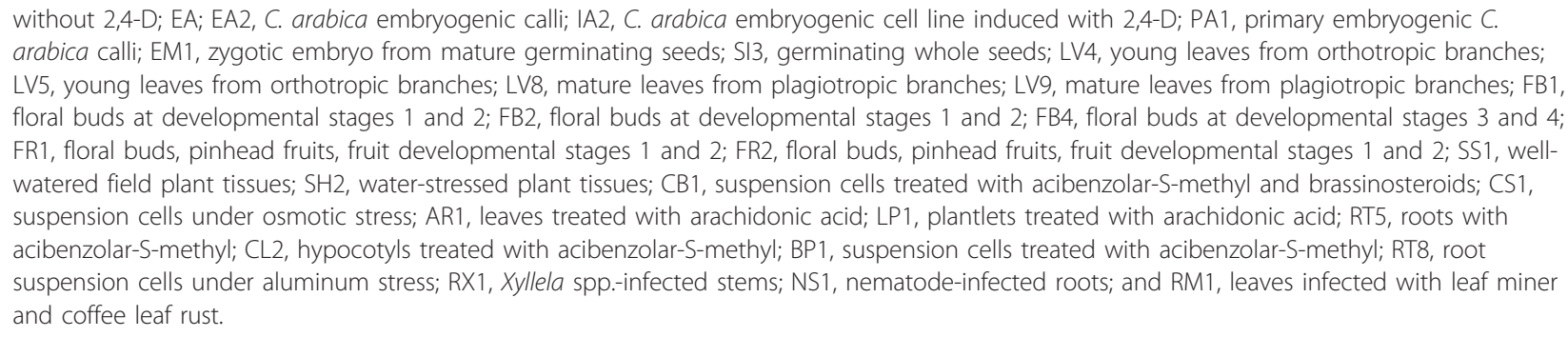

more details in the following section. The full annotation of differentially expressed genes can be accessed at http://www.lge.ibi.unicamp.br/coffea.

\section{Functional Classification of Differentially Expressed Genes and Prevalent Protein Families in C. arabica and C. canephora}

Based on the results of protein domain annotation, GO analysis, OrthoMCL data and Expression Hierarchical Clustering, we established functional categories to elucidate putative gene expression and its consequences in coffee development and environmental adaptations.

\section{Genes related to plant defense}

\section{Pathogenesis related proteins (PR)}

PRs are a heterogeneous group of plant proteins, inducible by biotic stresses $[59,60]$. Some of these proteins are effectors against pathogens and insects, while others are involved in reestablishing homeostasis after the stress [59].

Defensins or gamma-thionins (PR-12) are small, cationic, Cys-rich proteins structurally and functionally related to biocide defensins previously characterized in mammals and insects [61]. All EST reads that compose contigs encoding gamma-thionins from OrthoMCL family 12385 were expressed in tissues treated with benzothiadiazole BTH (BP1, CL2) or infected with nematodes (NS1). This OrthoMCL family was C. arabica-specific (Table 4), perhaps due to the lack of EST libraries from C. canephora plants treated with BTH. However, their specificity in Arabica suggests that these proteins rapidly evolved in Coffea spp., acquiring specific structural traits important for Coffea adaptation to pathogens.

The PR-10 protein family is a large group of PR proteins that are considered allergenic and exert ribonuclease activity, which is paralleled with cytokinin binding and anti-pathogenic roles [62]. In C. arabica, a PR-10 was found to be highly expressed in an incompatible reaction against the causative agent of coffee leaf rust, the biotrophic fungus Hemileia vastatrix [63]. A PR-10 from C. arabica (CaContig15067) was predicted to be more expressed in suspension cells treated with aluminum (Additional File 8). Concerning C. canephora, we observed an expression prevalence of PR-10 genes in late stages of fruit development (SE3 e SE4; Additional File 8). A proteomic analysis indicated that a C. arabica PR-10 was expressed only in the endosperm but not in zygotic embryos [64]. This result is similar to that found by Botton et al. [65], who reported the accumulation of a peach PR-10 during the fruit ripening stage.

One interesting result was the presence of a relatively large amount of chitinases (four contigs) and thaumatins (six contigs) in C. arabica calli libraries (PC1, EA1, IA1, IA 2 and PA1; Additional File 8; Figure 6B). Several reports indicate the participation of these PR proteins not only in plant defense but also during somatic embryogenesis [66-69]. The chitinases are hypothesized to have signaling functions during embryogenesis, because these proteins are able to rescue somatic embryos beyond globular stage [70]. Moreover, arabinogalactan proteins (AGPs), chitinases and thaumatins secreted in suspension-culture cells can promote the production of somatic embryos $[69,71]$. Our data strongly indicate a role for these PRs during coffee embryogenesis.

\section{Resistance Genes}

Most of the disease resistance genes ( $R$ genes) in plants encode nucleotide-binding site leucine-rich repeat (NBSLRR) proteins. They are engaged in the recognition of pathogens, being considered specific determinants of the plant immune response $[72,73]$. Upon annotation of OrthoMCL gene families, we detected 91 clusters and 36 clusters of CC-NBS-LRR proteins in C. arabica and $C$. canephora, respectively. In addition, some CC-NBS-LRR families were prevalent in C. arabica (Families 453, 3289, 2722) and in C. canephora (Family 6375; Table 4). The majority of clusters have higher identity with the PRF protein from tomato (with the exception of CaContig16622, which is more similar to RPP8 and LOV1 proteins). In a seminal report concerning the evaluation of resistance genes in coffee, 43 resistance gene analogues (RGAs) from both C. arabica and C. canephora were isolated, and it was verified that all RGAs are from the CCNBS-LRR subfamily [74]. Nevertheless, we identified a $C$. arabica contig analogous to TIR-NBS-LRR proteins (CaContig7327), with similarity to the nematode resistance potato proteins Gro1 [75] and Arabidopsis TAO1 
protein [76]. The extensive retraction (almost disappearance) of Coffea spp. TIR-NBS-LRR proteins is similar to that described in cereals and sugar beet $[77,78]$ and likely resulted from independent gene loss events in such different plant lineages $[74,77,78]$. The implications of the loss of TIR-type NBS-LRR genes and diversification of CC-NBS-LRRs deserve special attention in the understanding of coffee defense mechanisms.

\section{Genes Related to Abiotic Stress and Detoxification}

Genes related to abiotic stresses are potentially important in the recent scenario of harsh environmental changes, such as the increase of extreme temperatures and drought periods. Coffee plantations are threatened by global warming due to coffee's susceptibility to high temperatures and drought when these stresses occurs during flowering and fruit development [79]. The understanding of the relationship between tolerance/susceptibility mechanisms and abiotic stress is essential for the prospection of biotechnological and crop management strategies in coffee.

We inspected the genes that were more expressed in $C$. arabica drought stressed plants $(\mathrm{SH} 2)$ in comparison to well-watered plants conditions (SS1). Genes encoding RuBisCo activases (CaContig 5581 and 14729), a putative photosystem II type I chlorophyll a/b-binding (CAB) protein (CaContig5621) and a PSI-E subunit of photosystem I (CaContig5564) were preferentially expressed in the SH2 library (Additional File 8; Figure 6). Cramer et al. [80] also found similar expression patterns with $\mathrm{RuBisCo}$ activase and $C A B$ proteins during water and salinity stresses in grapevines. In drought stress, RuBisCo activase augments $\mathrm{RuBisCo}$ activity that is diminished as a consequence of a lower stomatal conductance caused by diffusion limitations through stomata and mesophyll [80]. Damages in PSII proteins are associated with the decrease of PSII chemistry caused by ROS [81]. The increase of photosystem I and II genes (CAB and PSI-E subunit) may be a mechanism to sustain photosystems susceptible to ROS attack [80]. These results indicate that the activation of the photosynthetic apparatus is a mechanism of drought stress mitigation in coffee plants.

Catalase controls $\mathrm{H}_{2} \mathrm{O}_{2}$ concentrations by dismuting $\mathrm{H}_{2} \mathrm{O}_{2}$ to water and oxygen. Montavon and Bortlik [82] detected increasing of catalase activity throughout coffee grain maturation. Among genes preferentially expressed in SH2 (Additional File 8; Figure 6A) CaContig13838 has similarity to Arabidopsis catalase 2, which is activated by drought stresses [83], supporting its involvement in the dehydration response in C. arabica. Another contig preferentially expressed in the SH2 library (CaContig13998) is similar to early light-induced proteins (ELIPs), thylakoid-target proteins that are similar to light harvesting complex (LHC) proteins (Additional File 8; Figure 6B).
ELIPs are reported to be up-regulated during various environmental stresses, such as cold and drought, and during fruit ripening $[84,85]$. ABA/WDS are proteins Cterminally enriched in His and Lys and are induced during ripening in pummel [86] and under water deficit stress in loblolly pine [87]. CaContig1691 appears to be one of the most expressed in water deficit stressed plants (Additional File 8; Figure 6B).

Other genes encoding proteins related to drought stress, such as dehydrins, metallothioneins and LEAs, were not differentially expressed in the SH2 library. However, we detected interesting profiles for these genes, especially for dehydrins and LEAs during fruit maturation and for metallothioneins preferentially expressed in libraries from plants treated with arachidonic acid, a polyunsaturated fatty acid present in pathogens (further details in Additional File 9).

\section{Plant Hormones: Auxin Regulation Genes and RALF-like Peptides}

Plant hormones (phytohormones) are crucial for a series of developmental mechanisms, such as organ initiation and development, resistance to stress and reproduction. Auxins are the most studied class of phytohormones, being implicated in cell division, cell elongation and cell differentiation [88]. Using OrthoMCL analysis, we identified a family of GH3-like proteins that is expanded in C. arabica (Family 9014; Table 4). GH3 enzymes conjugate amino acids to the auxin indole-3-acetic (IAA), decreasing the concentration of free auxin [89]. This mechanism is important in the regulation of IAA availability in plants. We also detected a family of Aux/IAA proteins that is prominent in C. arabica (Family 770; Table 4). Aux/IAA proteins have been shown to function as negative regulators of gene expression mediated by auxin response factor (ARF). A gene similar to auxin receptor TIR1 that promotes ubiquitin (Ub)-mediated degradation of Aux/IAA repressors was identified in C. arabica (CaContig 593). In addition, we also detected another putative auxin receptor in C. arabica, ABP1 (CaContig16576), a cupin-like protein that is implicated in early auxin responses [90].

Together with small lipophilic "classical phytohormones," small peptides have been described as factors involved in plant growth regulation [91]. Rapid alkalinization factor (RALF) is a small peptide initially isolated in tobacco that induces a rapid alkalinization in cell suspension and inhibits root growth in tomato and Arabidopsis seedlings [92]. Based on BLAST searching, we found a family of RALF peptides in C. arabica (two members) and C. canephora (five members). However, the evaluation of OrthoMCL families revealed that coffee has a particular family of small peptides slightly similar to RALFs (Family 8498; Table 4). These proteins contain the four 
cysteines in their C-termini required for RALF activity but are richest in Trp. Further, some members do not contain the conserved dibasic site (Additional File 10), which is essential for processing tomato and Arabidopsis RALFs [92-94]. The isolation and functional analysis of these coffee proteins/peptides constitute an important approach in order to verify whether they exert the same growth retarding effect as RALFs.

\section{Glycine-Rich Proteins}

The glycine-rich protein (GRP) superfamily is a large complex of plant proteins that share the presence of glycine-rich domains arranged in (Gly)n-X repeats [95]. Generally considered as involved in protein-protein interactions, GRPs have diverse functions and structural domains [96]. Evaluating hierarchical clusterization data, we found that several GRPs are preferentially expressed in suspension cells treated with BTH, brassinosteroids and $\mathrm{NaCl}$, as well as in embryogenic calli (Additional File 8). Those genes encode GRPs from Class I, which may contain a signal peptide for secretion followed by a glycine-rich region with GGGX repeats [95]. Other GRPs (CaContigs 1089, 3317, 10126) were found to be differentially expressed in plantlets and leaves treated with arachidonic acid (Additional File 8). These genes encode proteins containing signal peptides and are similar to class II GRPs, which contain a peptide motif rich in cysteine and tyrosine residues located in their C-termini [95]. However, a deeper annotation revealed that these coffee GRPs contain 12 cysteines instead of the six cysteines of the aforementioned class II GRPs (Additional File 11). These cysteine-rich domain proteins, such as class II AtGRP-3 and NtTLRP, were shown to interact with receptor protein kinase WAK1 [97] and to mediate the cross-linking of proteins to the cell wall [98]. We also detected the presence of some "specific" GRP OrthoMCL families in coffee (Table 4). Family 1231 is composed of class I GRPs, while family 4011 has GRPs from class II that contain six to 10 cysteines (Additional File 11). The diversification of GRPs in coffee is quite remarkable, especially in Class II and is probably important to coffee cell wall dynamics and signal transduction.

\section{Proteinase Inhibitors (PIs)}

The phytocystatins (PhyCys) are 12- to $16-\mathrm{kDa}$ plant proteinaceous inhibitors of Cys-proteases of the papain C1A family $[99,100]$. All cystatins contain three motifs involved in the interaction with their target enzymes: the reactive site $\mathrm{QxVxG}$, one or two glycine residues in the $\mathrm{N}$-terminal part of the protein, and an A/PW located downstream of the reactive site. In addition, PhyCys contain a consensus sequence ([LVI]-[AGT]-[RKE][FY]-[AS]-[VI]-x-[EDQV]-[HYFQ]-N) that conforms to a predicted secondary-helix structure [99]. Family 544 of hypothetical PhyCys was prevalent in coffee plants, containing 21 members in $C$. arabica and six members in $C$. canephora (Table 4). Proteins from family 544 are $\cong 10$ $\mathrm{kDa}$, contain a variation of the LARFAV-like domain and do not contain the canonical reactive site $\mathrm{QxVxG}$ but have a GG-X-YY motif (Additional File 12). Other OrthoMCL families (2703 and 942) were annotated as containing putative cystatins prevalent in coffee (Table 4; Additional File 12). All members of those three families have low but significant identities (30-40\%) with hypothetical cystatins from Arabidopsis (At5g47550), grape (XP_002274494.1) and Brassica oleracea (ABD64972).

Two C. canephora members from those families (CcContigs 7844 and 3825 ) were highly expressed in leaves from water deficit stressed plants (SH3; Additional File 8; Figure 6A). The majority of these new coffee cystatins do not have signal peptides (Additional File 12), likely being responsible for the regulation of endogenous protein turnover as hypothesized for alfalfa and barley cystatins $[101,102]$. In a recent phylogenomic analysis, it was proposed that cystatins had undergone a complex and dynamic evolution through gene losses and duplications [103]. This assignment may explain the expansion of cystatins in coffee and may indicate functional diversification of these proteins.

Members of the Potato type II (PotII) inhibitors (Pin2) family are PIs restricted to plants that belong to the MEROPS inhibitor family I20, clan IA [104]. Several Pin2 proteins have a multi-domain structure. However, sequences from coffee-prevalent proteins of OrthoMCL families 7241 and 10273 appear to be uni-domain Pin2 proteins (Additional File 13). Although we did not find any of the coffee Pin 2 genes preferentially expressed in EST libraries of stressed plants, predicted coffee Pin2 proteins contain signal peptides and, additionally, have $30-40 \%$ identity with a Pin2 protein of tobacco that confers tolerance to $\mathrm{NaCl}$ and resistance against herbivorous insects in transgenic plants [105]. In addition to the fact that PI expansions may be related to biotic stress regulation, PIs may also have an important role in proteolysis during coffee fruit development because the peptides and amino acids are precursors of coffee flavor and aroma (see below).

\section{Coffee Cup Quality Related Genes}

Coffee cup quality is a complex trait that is being unraveled. The components of coffee endosperm are the source of the precursors of aroma and flavor after roasting. The degradation of sucrose and cell wall polysaccharides generate reducing sugars, which react with amino acids during roasting through Maillard glycation reactions. This reaction gives rise to aromatic products, such as pyrazines, furans and aliphatic acids, which are 
associated with pleasant flavor and aroma [106]. Conversely, the bitterness of coffee is related to caffeine and chlorogenic acid content in coffee beans [107]. During our annotation, we give a panorama of genes related to coffee cup quality that were, by some means, emphasized in at least one of our bioinformatics analyses.

\section{Genes Related to Carbohydrate Metabolism}

Due to the importance of the amount and composition of carbohydrates to the final quality of the coffee beverage, the study of coffee bean carbohydrate synthesis and degradation is intense [5-7,108-112]. Coffee bean cell walls are mainly made of galactomannans, arabinogalactans and cellulose [108]. One interesting finding in our analysis was the prevalence of cellulose synthase superfamily proteins (pfam 03552; CesA) in C. arabica in relation to $C$. canephora (Figure 5 Additional File 5). CesA proteins interact in a cellulose synthase complex, and it is believed that each cell type contains three types of CesA subunits in a single complex [113]. Therefore, the broader origin of $C$. arabica ESTs may be the reason for the prevalence of $C$. arabica CesAs in comparison to C. canephora. The CesA family includes the "true" cellulose synthase genes and eight other families named 'cellulose synthase-like' genes CslA-CslH [114]. It was verified that some CslA proteins act in the synthesis of mannans and xyloglucans $[112,115,116]$. The orthologs of these Csl genes were found in our C. arabica EST data (CaContigs 3405 and 11680).

It is considered that the role of carbohydrates in the differences in cup quality between $C$. arabica and $C$. canephora is related to low molecular weight carbohydrate content, especially sucrose [117]. Arabica grains have a higher amount of sucrose (7.3-11.4\%) than $C$. canephora grains (4-5\%). Though sucrose is almost completely degraded during coffee bean roasting (0.4$2.8 \%$ dry weight), sucrose remains are thought to improve coffee sweetness and cup quality [118]. Privat et al. [6] found that the synthesis of sucrose phosphate synthase (SPS) was higher in late stages of C. arabica grains than in $C$. canephora, and invertase activity was lower in Arabica, likely due to the higher expression of invertase inhibitors in this species, justifying the higher sucrose content in C. arabica beans. Based on BLAST and OrthoMCL analysis, we found that Invertase Inhibitor 3 (InvI3) is part of a Coffea spp.-specific protein family (Family 14814; Table 4). These proteins have 20$30 \%$ identity to Zea mays invertase inhibitors from the pectin-methylesterase family $[6,119,120]$. We did not detect $C$. arabica ESTs encoding InvI3, likely due to the low coverage of fruit/seed libraries of this species. The presence of such a particular InvI in coffee may indicate new molecular mechanisms of invertase regulation.

The raffinose family oligosaccharides (RFOs) are soluble galactosyl-sucrose carbohydrates such as raffinose, stachyose and verbascose. Their participation in coffee seed development was assessed by Joet et al. [7], who indicated that RFOs were transiently present during the storage phase and remobilized during mid-stages of development to supply the extensive demand for galactose in galactomannan synthesis. Raffinose synthases (RS; EC 2.4.1.82) catalyze the synthesis of raffinose from sucrose and galactinol [121]. Our CDD-PFAM analysis indicated that $C$. arabica has a larger amount of RS than C. canephora (Figure 5). Such data seem to corroborate biochemical analyses that showed that grains from $C$. canephora contain reduced raffinose levels in comparison to Arabica [122,123]. A more careful inspection of RS C. arabica clusters revealed that these sequences were derived from diverse tissue libraries. The presence of more EST libraries from stressed plants in $C$. arabica may be the cause of such bias, because RFO accumulation has been associated with responses to abiotic stresses, protecting cellular metabolism from oxidative damage and drought [124,125]. Indeed, a recent analysis indicated that three $C$. arabica $\mathrm{RFO}$ synthase transcripts are induced by drought and saline stress (T.B. Santos, I. G. Budzinski, C.J. Marur, C.L. Petkowicz, L.F. Pereira, L.G. Vieira; unpublished results). Therefore, raffinose may exert dual functions in coffee: galactose reservoirs in coffee grains and protective roles in vegetative development.

It is assumed that the RFOs decrease in late stages of coffee bean development are caused by $\alpha$-D-Galactosidase ( $\alpha$-Gal; EC 3.2.1.22) activity. We identified three $\alpha$ Gal-encoding genes as more expressed in the late stages of C. canephora seed development (CcContigs 2650, 3171, 7083; Additional File 8; Figure 6A), data that agree with previous findings verifying increased $\alpha$-Gal activity during in vitro germination of coffee beans [126]. Together with $\alpha$-Gal, $\beta$-mannosidases (EC 3.2.1.25) and Endo $\beta$-mannanase (EC 3.2.1.78) are enzymes involved in the degradation of galactomannans during germination of seeds. Despite the fine analysis of C. arabica $\beta$-mannanases and $\alpha$-Gal $[109,126]$, there is no biochemical analysis of $\beta$-mannosidases activity in coffee of which we are aware. We found that $\beta$-mannosidases are preferentially expressed in germinating seeds of C. arabica and C. canephora (CaContig 3009, CcContig6678; Figure 6; Additional File 8), a similar pattern in comparison to $\alpha-\mathrm{Gal}$ from C. canephora (CcContig 6678; Additional File 8).

\section{Amino Acid Content: Storage Protein Synthesis and Protease Expression}

As cited above, proteins and amino acids are also fundamental for the generation of flavor and aroma-related Maillard-end products. In effect, the level of protein synthesis during early fruit stages, the amount of seed storage proteins (SSPs) in the endosperm and the 
relationship between proteinases and their inhibitors during seed development are all factors that determine the amino acid content in mature beans. Examining the expression profile of the SE2 library, we found a series of ribosomal proteins expressed in this stage of seed maturation (Figure 6A; Additional File 8), indicating an intense cellular effort in translation. Many SSPs are enriched in cysteines, which confer high stability to these proteins, an important factor for storage proteins. These cysteines are also a source of sulfur used in seed germination. Two genes involved in cysteine metabolism, protein folding and sulfur metabolism were preferentially expressed in the early stage of $C$. canephora seed maturation (SE2 library; Figure 6A). CcContigs 7827 and 99 encode a cysteine synthase (O-acetylserine (thiol) lyase) (EC 4.2.99.8), an enzyme that synthesizes cysteine [127], and a protein disulfide isomerase (PDI), an enzyme that catalyzes the formation and breakage of disulfide bonds between cysteine residues within proteins as they fold [128], respectively.

In coffee, the Cupin family protein $11 \mathrm{~S}$ globulin represents $45 \%$ of the total protein in the endosperm (corresponding to $5-7 \%$ of coffee bean dry weight) [129] and is probably one of the main sources of nitrogen during coffee bean roasting. Our expression hierarchical clustering analysis indicated that two $11 \mathrm{~S}$ globulin genes were preferentially expressed in C. arabica fruit libraries (CaContigs 12252 and13966; Additional File 8), and one was more highly expressed in the late stages of C. canephora seed development (i.e., 42 weeks after pollination) (CcContig 4069; Additional File 8). This contig was the second most abundant in the $C$. canephora database (Additional File 7) after a $2 \mathrm{~S}$ albumin (CcContig1385; Additional File 7). We also identified a cysteine and an aspartic protease preferentially expressed in the last phase of Arabica seed maturation (CaContigs 7768 and 8165; Additional File 8). The coincidence of expression profiles of important storage proteins such as $11 \mathrm{~S}$ globulin and $2 \mathrm{~S}$ albumin together with proteinases is an indication that the release of free amino acids or small peptides that contribute to coffee cup quality can occur in the final stage of coffee maturation.

\section{Secondary Metabolism: Caffeine, Trigoneline and Chlorogenic Acid}

Other precursors of flavor and aroma in coffee are secondary metabolites, such as alkaloids (caffeine and trigoneline) and phenylpropanoid chlorogenic acid (CGA). These three components, together with sucrose, seem to be the main factors influencing coffee quality, because sucrose and trigoneline enhance coffee quality, while CGA and caffeine confer bitter taste [7,107,130-133]. The comparison between the two coffee species showed that $C$. arabica has more trigoneline and sucrose, and C. canephora contains more CGA and caffeine [131].
Despite intense annotation, our data did not reveal any outstanding results concerning the differential expression of the genes in the metabolic pathways of these compounds during fruit development or any interesting difference between C. arabica and C. canephora plants.

\section{Conclusion}

We assembled ESTs from C. arabica and C. canephora and applied a diverse array of bioinformatics tools to extract information about gene content features, transcriptome changes and novel genes and gene families. The results concerning the prevalence of proteins related to sugar metabolism in C. arabica and signal transduction in C. canephora can be correlated with agronomical characteristics of each species due to the better cup quality of $C$. arabica and the high tolerance to specific stresses in C. canephora plants. Despite knowing that comparisons between these Coffea species data should be carefully inspected, our initiative established possible transcriptomic elements that could guide the coffee scientific community in unraveling the molecular mechanisms that distinguish these two extremely important Coffea species. In addition, the annotation of coffee-specific/prominent genes adds new elements to genomic initiatives that are searching for traits that could differentiate coffee from other Asteridae species. In a recent report, Vidal et al. [30] showed that $C$. arabica displays differential expression of homeologous genes and suggested that C. arabica ancestral subgenomes encode proteins involved in different physiological mechanisms, adding a new element of investigation concerning gene expression regulation in coffee plants.

All data presented here are available at http://www.lge. ibi.unicamp.br/coffea. We believe that such data are a valuable aid to the interpretation of coffee development, providing insights that could help coffee breeding programs and indicating potential targets for functional analysis and biotechnology products of such socially and economically important species.

\section{Methods}

EST assembly and trimming

ESTs from C. arabica $(187,142)$ and C. canephora $(78,470)$ were derived from 43 libraries collected by the BCGP and from 8 libraries of C. canephora EST sequencing initiative of the Nestlé Research Center (8). The Brazilian project sources were mainly two C. arabica genotypes (Catuai and Mundo Novo, with the exception of germinating seeds from cv. Rubi) and one C. canephora genotype (Conillon). The Cornell-Nestlé project EST sources were five different varieties of C. canephora [22]. Sequences were trimmed using BDTrimmer to remove ribosomal sequences, polyA/T tails, low quality sequences, vector sequences (UniVec database) and $E$. 
coli contaminants [134]. EST assembling was executed using the CAP3 program, with a minimum similarity threshold of $90 \%$ and a minimum overlap of 40 bases. ESTs from each species were assembled separately, and the genotypes were assembled together into the same species. After the assembly, nucleic acid contamination from bacterial organisms that were not removed during trimming analysis (putative endophytes of coffee) was detected using BLASTN against a version of the NT database containing only bacteria (NT-bac) and BLASTX against the NR database. The results against NT-bac with E-values $>1 \mathrm{e}^{-40}$ and the percent of identical nucleotides $>80 \%$ were considered bacterial contamination. In addition, hits against NR with a percent of identity $>30 \%$ and all of the hits against bacteria were considered bacterial contamination. All of the BCGP ESTs were submitted to GenBank with accession numbers GT640310-GT640366, GT669291-GT734396, GW427076 - GW492625 (C. arabica) and GT645618GT658452 (C. canephora).

\section{Single Nucleotide Polymorphism (SNP) analyses and GC content}

QualitySNP [24] was used to analyze polymorphisms present in C. arabica and C. canephora. QualitySNP uses three quality filters for the identification of reliable SNPs. The first filter screens for all potential SNPs. False SNPs caused by sequencing errors are identified by the chromatogram quality given by Phred. The second filter is the core filter, which uses a haplotype-based strategy to detect reliable SNPs. The clusters with potential paralogs are identified using the differences in SNP number between potential haplotypes of the same contig. All potential haplotypes consisting of only one sequence are removed, and singleton SNPs that are not linked to other polymorphisms are not considered. This may lead to an underestimation of nucleotide diversity but assures that false positives will be discarded. The last filter screens SNPs by calculating a confidence score based on sequence redundancy and base quality. To label each polymorphism as synonymous or non-synonymous, the correct open reading frame (ORF) of each sequence was identified by looking for similarity calculated with the FASTA algorithm against the Uniprot databank http://www.uniprot.org using an E-value threshold of -05 . The alignments were analyzed with QualitySNP script GetnonsySNPfasty, which corrects frame shifts and attempts to expand the 3' end until the next stop codon and the 5' end until the next ATG codon. This script identifies if the polymorphism changes the amino acid, labeling each polymorphism as non-synonymous (KA) or synonymous (KS). This information was used to calculate KA/KS ratios for positive selection using kaks calculator software [135]. All of the ORFs predicted in QualitySNP were used to calculate the GC content of
C. arabica and C. canephora. A total of 1,380 full length sequences $>200 \mathrm{bp}$ of Arabidopsis thaliana were extracted from Genbank. Sequences of Solanum lycopersicum were also randomly retrieved from the Kazusa http://www.kazusa. or.jp/jsol/microtom/indexj.html and SGN databanks [23]. Total GC and GC3 were calculated for each sequence and plotted in a histogram graph with 100 classes, which were smoothed by using the average of each three sets of classes.

\section{Automatic Functional Annotation, Metabolic Pathways and Evaluation of Protein Domains}

The complete set of ESTs from C. arabica and C. canephora were automatically annotated using the AutoFACT program [31]. AutoFACT summarizes results of BLAST similarity searches against nucleotide, protein and domain databases in functional annotation. The databases used were Uniref100, Uniref90, NCBI-nr, KEGG and CDD (E-value $\leq 1 \mathrm{E}-5)$. The annotation was submitted to the Pathologic module of the Pathway Tools program (version 13.0) in order to generate metabolic maps. Pathologic module looks at the product name and E.C. number of annotations and imports the pathways likely to be present from the reference database (MetaCyc). The C. arabica and C. canephora metabolic maps were compared with PlantCyc, which contains curated information about pathways present in $>250$ plant species. The divergence among the maps was manually annotated to eliminate false positives. To evaluate protein domains, ESTs were submitted to similarity searches against the CDD-PFAM database using RPS-BLAST (Evalue $\left.\leq 1 \mathrm{e}^{-10}\right)$. Data were normalized by dividing the number of clusters from each CDD-PFAM by the total number of hits from each species against CDD-PFAM.

\section{Gene Ontology Analyses}

Coffee datasets were annotated and mapped for the gene ontologies "Biological Process" and "Molecular Function" (only level 3) by Blast2go [43]. Blast2go lists all gene ontology terms found in biological processes and molecular functions found in each dataset and associates the amount of sequences with each term. These data were normalized to the total number of sequences that were labeled with a gene ontology term. Hypergeometric distribution statistical analysis [44] was applied in the datasets from fruit and leaf to find the sub- and overestimated GO terms in each species.

\section{Orthologous Clustering (Ortho-MCL)}

The Ortho-MCL algorithm [47] was applied to generate orthologous groupings. Two different datasets were used: i) the annotated proteins from the available complete genomes of $A$. thaliana (27,379 proteins), O. sativa (56,797 proteins), Ricinus communis (31,221 proteins) and Glycine $\max (66,210$ proteins) and ii) the proteins 
predicted by FrameDP software [48] from the available EST assemblies for C. arabica (28,585 predicted proteins), C. canephora (16,477 predicted proteins) and $S$. lycopersicum (52,437 predicted proteins). All proteins were compared (all against all) using BLASTP, and a score for each pair of proteins $(\mathrm{u}, \mathrm{v})$ with significant BLAST hits was assigned (E-value $1 \mathrm{e}^{-5}$; with at least $50 \%$ of similarity). Based on these scores, the MCL algorithm was applied to find clusters in this graph. The protocol used is described at http://lge.ibi.unicamp.br/Ortho_MCL_UserGuide.txt.

\section{Gene Expression Hierarchical Clustering Analysis}

For in silico expression analysis, contig and singlet frequencies across the libraries were obtained from the dataset derived from the CAP3 assembly. The frequency of a contig over a library represents its transcript abundance. Only contigs containing more than two ESTs were used for transcript profiling. Differentially expressed contigs were identified using two statistical tests, $\mathrm{R}$ [55] and AC [56], with the webtool IDEG6 [57]. In R statistics, a threshold p-value of 0.05 (95\% confidence) was used with Bonferroni correction. AC statistics were calculated for pairwise combinations of all libraries. Under this criterion, a contig was considered of significant interest if the AC statistics of at least one library against all of the other libraries were lower than the threshold 0.05 . The resulting differentially expressed contigs were obtained with the union of the two sets above. Each library frequency was then normalized by the frequency of the contig.

In an attempt to cluster elements that are similar (in some sense), hierarchical clustering [136] of the differentially expressed contigs was performed using MatlabR2009a (The Mathworks). Hierarchical algorithms attempt to group the differentially expressed contigs based on the expression profile of these contigs in the libraries. The clustering of the rows (contigs) was performed, generating a heat map and a dendrogram. The libraries were manually sorted according to tissue sources and stress conditions, visually creating two libraries groups: "development" libraries and "stress" libraries.

\section{Additional material}

Additional file 1: Description of Brazilian Coffee Genome Project ESTs and CDNA libraries. Word file describing the methods used for the production of Brazilian coffee ESTs libraries, the tissues and experimental conditions used.

Additional file 2: Number of contigs composed from sequence originated from one or more libraries. TIF file containing a figure depicting the correlation between number of contigs vs number of libraries.

Additional file 3: Global data of SNP detection in C. arabica and C. canephora EST datasets. Word file containing an overall analysis of SNPs from C. arabica and C. canephora contigs.
Additional file 4: Annotation of KA/KS ratio in Coffea spp. contigs Word file containing the annotation of Top $20 \mathrm{C}$. arabica contigs with highest and lowest KA/KS ratio (A); Annotation of Top 20 C. canephora contigs with highest and lowest KA/KS ratio (B). ID: Contig number; KS: rate of synonymous substitutions, KA: rate of non-synonymous substitutions; KA/KS: KA to KS ratio; First Hit (BLASTX-NR): Most similar sequence in GenBank; E-value: E-value of most similar sequence; Annotation: automatic annotation based in AutoFACT results.

Additional file 5: Top 20 Coffea spp. PFAM families. Word file containing the ranking of PFAM families in C. arabica and C. canephora.

Additional file 6: Annotation of Top 20 genes with the widest distribution among Coffea spp. cDNA libraries. Word file containing the ranking of genes distributed throughout coffee EST libraries. ID: Contig number; \#: number of libraries represented in each contig; \#ESTs: number of ESTs that compose each contig; First Hit (BLASTX-NR): Most similar sequence in GenBank; E-value: E-value of most similar sequence; Annotation: automatic annotation based in AutoFACT results.

Additional file 7: Annotation of 20 genes with the highest expression among Coffea spp. cDNA libraries. Word file containing the ranking of genes more expressed in coffee EST libraries. ID: Contig number; \#: number of libraries represente in each contig; \#ESTs: number of ESTs that compose each contig; First Hit (BLASTX-NR): Most similar sequence in GenBank; E-value: E-value of most similar sequence; Annotation: automatic annotation based in AutoFACT results.

Additional file 8: Annotation of selected differentially expressed genes in coffee EST libraries according to hierarchical clustering analysis. Excel file containing the annotation of genes with differential expression profile in coffee EST libraries according to hierarchical clustering analysis. Worksheet CA: C. arabica contigs; Worksheet CC: C. canephora contigs. Libraries: Tissues and organs used in the libraries construction; Nomenclature: code of the library; Contig ID: Contig number; Annotation: automatic annotation based in AutoFACT results.

Additional file 9: Results concerning some genes related with drought stress (Dehydrins, LEAs and Metallothioneins). Word file describing results and a brief discussion about dehydrins, LEAs and Metallothioneins expressed in coffee EST libraries.

Additional file 10: RALF and RALF-like peptides. Word file containing the sequences of RALF and RALF-like peptides expressed in coffee. In magenta: dibasic sites; in yellow: cysteine residues.

Additional file 11: OrthoMCL families of Glycine Rich Proteins (GRP) Word file containing the sequences of Glycine Rich Proteins expressed in coffee. In yellow: cysteine residues; Underlined: signal peptide for secretion.

Additional file 12: OrthoMCL families of Cystatins. Word file containing the sequences of Cystatins expressed in coffee. In green: variation of LARFAV motif; in yellow: new motif GG-X-YY; in blue: QWAG motif.

Additional file 13: OrthoMCL families of Pinll Serine Proteinase Inhibitors. Word file containing the sequences of Pinll Serine Proteinase Inhibitors in coffee.

\section{Acknowledgements}

We especially thank all sequencing and annotation technician teams for their excellent work and support, and Paulo José Teixeira (LGE, UNICAMP) for comments about the manuscript. ROV obtained a PhD fellowship from Fundação de Amparo à Pesquisa do Estado de São Paulo (FAPESP; 2007/ 51031-2). MFC and GGLC received TT-4 Information Technology fellowships from the Applied and Environmental Genomes (AEG) initiative from FAPESP. Brazilian Coffee Genome Project Consortium was sponsored by Consórcio Brasileiro de Pesquisa e Desenvolvimento do Café (CBP\&D Café), Empresa Brasileira de Pesquisa Agropecuária (EMBRAPA) and FAPESP. Brazilian Coffee Genome Project Consortium:

MP Maluf (Embrapa Café, Campinas), O Guerreiro-Filho, PR Furlani (IAC, Campinas) and P Mazzafera (UNICAMP, Campinas) performed plant experimentation and gave plant material to ESTs libraries construction; A Mehta, DC Monte, E Romano, ERP de Almeida, EVS Albuquerque, JB Teixeira, 
MF Grossi-de-Sá (EMBRAPA, Cenargen, Brasília), CA Labate, CB MonteiroVitorello, H Carrer, EC Jorge, LEA Camargo, LL Coutinho (ESALQ, USP, Piracicaba), CL Marino, EU Kuramae (UNESP, Botucatu), EA Giglioti (FAM, Adamantina), EGM Lemos, MIT Ferro, MVF Lemos (UNESP, Jaboticabal), ET Kimura, MA Van-Sluys, MC de Oliveira (USP, São Paulo), HE Sawazaki, WJ Siqueira (IAC, Campinas), HFA El -Dorry (American University in Cairo, Egypt), MA Machado (IAC, Cordeirópolis), MHS Goldman (USP, Ribeirão Preto), MTS Eira (EMBRAPA Café, Brasília), P Arruda (UNICAMP, Campinas), R Harakava (Instituto Biológico, São Paulo), RLBC Oliveira (UMC, Mogi das Cruzes), SM Tsai (CENA, USP, Piracicaba), SM Zingaretti (UNAERP, Ribeirão Preto) performed EST libraries construction and participated in sequencing effort; EF Formighieri (Embrapa Agroenergia, Braślia), FR da Silva, MMC Costa (EMBRAPA, Cenargen, Brasília) and JP Kitajima (SBIB Albert Einstein, São Paulo) performed annotation and bioinformatics.

\section{Author details}

'Centro de Recursos Genéticos Vegetais, Instituto Agronômico de Campinas, CP 28, 13001-970, Campinas-SP, Brazil. ²Laboratório de Genômica e Expressão, Departamento de Genética, Evolução e Bioagentes, Instituto de Biologia, Universidade Estadual de Campinas, CP 6109, 13083-970, CampinasSP, Brazil. " Laboratório Nacional de Biociências (LNBio), CP 6192, 13083-970, Campinas-SP, Brazil. ${ }^{4}$ Centro Nacional de Processamento de Alto Desempenho em São Paulo, Universidade Estadual de Campinas, CP 6141, 13083-970, Campinas, SP, Brazil. ${ }^{5}$ Embrapa Café - Instituto Agronômico do Paraná, Laboratório de Biotecnologia Vegetal, CP 481, 86001-970, LondrinaPR, Brazil. ${ }^{6}$ Núcleo de Biotecnologia-NTBio, Embrapa Recursos Genéticos e Biotecnologia, Parque Estação Biológica, CP 02372, 70770-900, Brasília-DF, Brazil. ' Instituto Agronômico do Paraná, Laboratório de Biotecnologia Vegetal, CP 481, CEP 86001-970, Londrina-PR, Brazil.

\section{Authors' contributions}

JMCM: ESTs and cluster re-annotations, conception of bioinformatics analyses, evaluation and interpretation of GC content, Ortho-MCL, CDDPFAM, Gene Ontology and Hierarchical clustering data, conception and writing of the manuscript; ROV: EST assembly, conception of bioinformatics analyses, GC content and SNP analyses and evaluation, Gene Ontology and Ortho-MCL analysis; MFC: EST assembly, conception of bioinformatics analyses and CDD-PFAM analysis; EKT: Hierarchical clustering analysis; LPP: AutoFACT and Metabolic Pathways analysis; GGLC: EST assembly and OrthoMCL analysis; LFPP: SNP evaluation and revision of the manuscript; ACA: Coordination of EMBRAPA EST libraries and revision of the manuscript; CAC: Coordination of AEG/FAPESP EST libraries and revision of the manuscript; LGEV: Coordination of the EST consortium and revision of the manuscript; GAGP: coordination of the bioinformatics group and elaboration of the final manuscript. All authors read and approved the final manuscript.

Received: 16 May 2010 Accepted: 8 February 2011

Published: 8 February 2011

\section{References}

1. Pay E: The market for organic and fair-trade coffee. FAO Rome 2009.

2. Charrier A, Berthaud J: Botanical classification of coffee. In Coffee: botany, biochemistry, and production of beans and beverage. New York Edited by: Clifforf MN, Wilsson KC 1985, 13-47.

3. Lashermes P, Combes MC, Robert J, Trouslot P, D'Hont A, Anthony F, Charrier A: Molecular characterisation and origin of the Coffea arabica $\mathrm{L}$. genome. Mol Gen Genet 1999, 261(2):259-266.

4. Anthony F, Combes C, Astorga C, Bertrand B, Graziosi G, Lashermes P: The origin of cultivated Coffea arabica L. varieties revealed by AFLP and SSR markers. Theor Appl Genet 2002, 104(5):894-900.

5. Geromel C, Ferreira LP, Guerreiro SM, Cavalari AA, Pot D, Pereira LF, Leroy T, Vieira LG, Mazzafera P, Marraccini P: Biochemical and genomic analysis of sucrose metabolism during coffee (Coffea arabica) fruit development. J Exp Bot 2006, 57(12):3243-3258.

6. Privat I, Foucrier S, Prins A, Epalle T, Eychenne M, Kandalaft L, Caillet V Lin C, Tanksley S, Foyer C, et al: Differential regulation of grain sucrose accumulation and metabolism in Coffea arabica (Arabica) and Coffea canephora (Robusta) revealed through gene expression and enzyme activity analysis. New Phytol 2008, 178(4):781-797.

7. Joet T, Laffargue A, Salmona J, Doulbeau S, Descroix F, Bertrand B, de Kochko A, Dussert S: Metabolic pathways in tropical dicotyledonous albuminous seeds Coffea arabica as a case study. New Phytol 2009, 182(1):146-162.

8. Leroy T, Marraccini P, Dufour M, Montagnon C, Lashermes P, Sabau X, Ferreira LP, Jourdan I, Pot D, Andrade AC, et al: Construction and characterization of a Coffea canephora BAC library to study the organization of sucrose biosynthesis genes. Theor Appl Genet 2005, 111(6):1032-1041.

9. Wintgens JN: Coffee: growing, processing, sustainable production. Weinheim 2004.

10. Maluf MP, Silvestrini M, Ruggiero LMD, Guerreiro O, Colombo CA: Genetic diversity of cultivated Coffea arabica inbred lines assessed by RAPD, AFLP and SSR marker systems. Scientia Agricola 2005, 62(4):366-373.

11. Vettore AL, da Silva FR, Kemper EL, Souza GM, da Silva AM, Ferro MI, Henrique-Silva F, Giglioti EA, Lemos MV, Coutinho LL, et al: Analysis and functional annotation of an expressed sequence tag collection for tropical crop sugarcane. Genome Res 2003, 13(12):2725-2735.

12. da Silva FG, landolino A, Al-Kayal F, Bohlmann MC, Cushman MA, Lim H, Ergul A, Figueroa R, Kabuloglu EK, Osborne C, et al: Characterizing the grape transcriptome. Analysis of expressed sequence tags from multiple Vitis species and development of a compendium of gene expression during berry development. Plant Physiol 2005, 139(2):574-597.

13. Verza NC, TR ES, Neto GC, Nogueira FT, Fisch PH, de Rosa VE, Rebello MM, Vettore AL, da Silva FR, Arruda P: Endosperm-preferred expression of maize genes as revealed by transcriptome-wide analysis of expressed sequence tags. Plant Mol Biol 2005, 59(2):363-374.

14. Ramirez M, Graham MA, Blanco-Lopez L, Silvente S, Medrano-Soto A, Blair MW, Hernandez G, Vance CP, Lara M: Sequencing and analysis of common bean ESTs. Building a foundation for functional genomics. Plant Physiol 2005, 137(4):1211-1227.

15. Sakurai T, Plata G, Rodriguez-Zapata F, Seki M, Salcedo A, Toyoda A, Ishiwata A, Tohme J, Sakaki Y, Shinozaki K, et al: Sequencing analysis of 20,000 full-length cDNA clones from cassava reveals lineage specific expansions in gene families related to stress response. BMC Plant Biol 2007, 7:66.

16. Argout X, Fouet O, Wincker P, Gramacho K, Legavre T, Sabau X, Risterucci AM, Da Silva C, Cascardo J, Allegre M, et al: Towards the understanding of the cocoa transcriptome: Production and analysis of an exhaustive dataset of ESTs of Theobroma cacao L. generated from various tissues and under various conditions. BMC Genomics 2008, 9:512.

17. Alexandrov NN, Brover W, Freidin S, Troukhan ME, Tatarinova TV, Zhang H, Swaller TJ, Lu YP, Bouck J, Flavell RB, et al: Insights into corn genes derived from large-scale cDNA sequencing. Plant Mol Biol 2009, 69(12):179-194.

18. Marques MC, Alonso-Cantabrana H, Forment J, Arribas R, Alamar S, Conejero V, Perez-Amador MA: A new set of ESTs and CDNA clones from full-length and normalized libraries for gene discovery and functional characterization in citrus. BMC Genomics 2009, 10:428.

19. Leroy T, Henry AM, Royer M, Altosaar I, Frutos R, Duris D, Philippe R: Genetically modified coffee plants expressing the Bacillus thuringiensis cry1Ac gene for resistance to leaf miner. Plant Cell Rep 2000, 19(4):382-389.

20. Ogita S, Uefuji H, Yamaguchi Y, Koizumi N, Sano H: Producing decaffeinated coffee plants. Nature 2003, 423(6942):823.

21. Vieira LGE, Andrade AC, Colombo CA, Moraes AHA, Metha A, Oliveira AC, Labate CA, Marino CL, Monteiro-Vitorello CB, Monte DC, et al: Brazilian coffee genome project: an EST-based genomic resource. Brazil J Plant Physiol 2006, 18:95-108.

22. Lin C, Mueller LA, MC Carthy J, Crouzillat D, Petiard V, Tanksley SD: Coffee and tomato share common gene repertoires as revealed by deep sequencing of seed and cherry transcripts. Theor Appl Genet 2005, 112(1):114-130.

23. Mueller LA, Solow TH, Taylor N, Skwarecki B, Buels R, Binns J, Lin C, Wright MH, Ahrens R, Wang Y, et al: The SOL Genomics Network: a comparative resource for Solanaceae biology and beyond. Plant Physiol 2005, 138(3):1310-1317.

24. Tang J, Vosman B, Voorrips RE, van der Linden CG, Leunissen JA: QualitySNP: a pipeline for detecting single nucleotide polymorphisms and insertions/deletions in EST data from diploid and polyploid species. BMC Bioinformatics 2006, 7:438.

25. Carels N, Bernardi G: Two classes of genes in plants. Genetics 2000, 154(4):1819-1825. 
26. Glemin S, Bazin E, Charlesworth D: Impact of mating systems on patterns of sequence polymorphism in flowering plants. Proc Biol Sci 2006, 273(1604):3011-3019.

27. Picoult-Newberg L, Ideker TE, Pohl MG, Taylor SL, Donaldson MA, Nickerson DA, Boyce-Jacino M: Milling SNPs from EST databases. Genome Res 1999, 9(2):167-174

28. Batley J, Hayes PK: Development of high throughput single nucleotide polymorphism genotyping for the analysis of Nodularia (Cyanobacteria) population genetics. J Phycol 2003, 39(1):248-252.

29. Dantec LL, Chagne D, Pot D, Cantin O, Garnier-Gere P, Bedon F, Frigerio JM, Chaumeil $P$, Leger $P$, Garcia $V$, et al: Automated SNP detection in expressed sequence tags: statistical considerations and application to maritime pine sequences. Plant Mol Biol 2004, 54(3):461-470.

30. Vidal RO, Mondego JM, Pot D, Ambrosio AB, Andrade AC, Pereira LF, Colombo CA, Vieira LG, Carazzolle MF, Pereira GA: A high-throughput data mining of SNPs in Coffea spp ESTs suggests differential homeologous gene expression in the allotetraploid Coffea arabica. Plant Physiol 2010, 154(3):1053-1066.

31. Koski LB, Gray MW, Lang BF, Burger G: AutoFACT: an automatic functional annotation and classification tool. BMC Bioinformatics 2005, 6:151.

32. Jaillon O, Aury JM, Noel B, Policriti A, Clepet C, Casagrande A, Choisne N, Aubourg $S$, Vitulo $N$, Jubin $C$, et al: The grapevine genome sequence suggests ancestral hexaploidization in major angiosperm phyla. Nature 2007, 449(7161):463-467

33. Lyons E, Pedersen B, Kane J, Alam M, Ming R, Tang H, Wang X, Bowers J, Paterson A, Lisch D, et al: Finding and comparing syntenic regions among Arabidopsis and the outgroups papaya, poplar, and grape: CoGe with rosids. Plant Physiol 2008, 148(4):1772-1781.

34. Guyot R, de la Mare M, Viader V, Hamon P, Coriton O, Bustamante-Porras J, Poncet V, Campa C, Hamon S, de Kochko A: Microcollinearity in an ethylene receptor coding gene region of the Coffea canephora genome is extensively conserved with Vitis vinifera and other distant dicotyledonous sequenced genomes. BMC Plant Biol 2009, 9:22.

35. Cenci A, Combes MC, Lashermes P: Comparative sequence analyses indicate that Coffea (Asterids) and Vitis (Rosids) derive from the same paleohexaploid ancestral genome. Mol Genet Genomics 2010, 283(5):493-501.

36. Yang Z, Bielawski JP: Statistical methods for detecting molecular adaptation. Trends Ecol Evol 2000, 15(12):496-503.

37. Roth C, Liberles DA: A systematic search for positive selection in higher plants (Embryophytes). BMC Plant Biol 2006, 6:12.

38. Novaes E, Drost DR, Farmerie WG, Pappas GJ, Grattapaglia D, Sederoff RR, Kirst M: High-throughput gene and SNP discovery in Eucalyptus grandis, an uncharacterized genome. BMC Genomics 2008, 9:312.

39. Stukenbrock EH, McDonald BA: Population genetics of fungal and oomycete effectors involved in gene-for-gene interactions. Mol Plant Microbe Interact 2009, 22(4):371-380

40. Karp PD, Ouzounis CA, Moore-Kochlacs C, Goldovsky L, Kaipa P, Ahren D, Tsoka S, Darzentas N, Kunin V, Lopez-Bigas N: Expansion of the BioCyc collection of pathway/genome databases to 160 genomes. Nucleic Acids Res 2005, 33(19):6083-6089.

41. Vitte C, Panaud O: LTR retrotransposons and flowering plant genome size: emergence of the increase/decrease model. Cytogenet Genome Res 2005, 110(1-4):91-107.

42. Lopes FR, Carazzolle MF, Pereira GA, Colombo CA, Carareto CM: Transposable elements in Coffea (Gentianales: Rubiacea) transcripts and their role in the origin of protein diversity in flowering plants. Mol Genet Genomics 2008, 279(4):385-401.

43. Conesa A, Gotz S: Blast2GO: A Comprehensive Suite for Functional Analysis in Plant Genomics. Int J Plant Genomics 2008, 2008:619832.

44. Martin D, Brun C, Remy E, Mouren P, Thieffry D, Jacq B: GOToolBox: functional analysis of gene datasets based on Gene Ontology. Genome Biol 2004, 5(12):R101.

45. Frenal K, Callebaut I, Wecker K, Prochnicka-Chalufour A, Dendouga N, ZinnJustin S, Delepierre M, Tomavo S, Wolff N: Structural and functional characterization of the TgDRE multidomain protein, a DNA repair enzyme from Toxoplasma gondii. Biochemistry 2006, 45(15):4867-4874.

46. Li L, Stoeckert CJ, Roos DS: OrthoMCL: identification of ortholog groups for eukaryotic genomes. Genome Res 2003, 13(9):2178-2189.

47. Chen F, Mackey AJ, Stoeckert CJ, Roos DS: OrthoMCL-DB: querying a comprehensive multi-species collection of ortholog groups. Nucleic Acids Res 2006, , 34 Database: D363-368.
48. Gouzy J, Carrere S, Schiex T: FrameDP: sensitive peptide detection on noisy matured sequences. Bioinformatics 2009, 25(5):670-671.

49. Luo ZY, Lu QH, Liu SP, Chen XH, Luo JQ, Tan LJ, Hu WX: Screening and identification of novel genes involved in biosynthesis of ginsenoside in Panax ginseng plant. Acta biochim biophys Sinica 2003, 35(6):554-560.

50. Salmona J, Dussert S, Descroix F, de Kochko A, Bertrand B, Joet T: Deciphering transcriptional networks that govern Coffea arabica seed development using combined CDNA array and real-time RT-PCR approaches. Plant Mol Biol 2008, 66(1-2):105-124.

51. Barsalobres-Cavallari CF, Severino FE, Maluf MP, Maia IG: Identification of suitable internal control genes for expression studies in Coffea arabica under different experimental conditions. BMC Mol Biol 2009, 10:1.

52. Cruz F, Kalaoun S, Nobile P, Colombo C, Almeida J, Barros LMG, Romano E, Grossi-de-Sa MF, Vaslin M, Alves-Ferreira M: Evaluation of coffee reference genes for relative expression studies by quantitative real-time RT-PCR. Mol Breed 2009, 23(4):607-616.

53. Vandesompele J, De Preter K, Pattyn F, Poppe B, Van Roy N, De Paepe A, Speleman F: Accurate normalization of real-time quantitative RT-PCR data by geometric averaging of multiple internal control genes. Genome Biol 2002, 3(7):RESEARCH0034.

54. Linster CL, Gomez TA, Christensen KC, Adler LN, Young BD, Brenner C, Clarke SG: Arabidopsis VTC2 encodes a GDP-L-galactose phosphorylase, the last unknown enzyme in the Smirnoff-Wheeler pathway to ascorbic acid in plants. J Biol Chem 2007, 282(26):18879-18885.

55. Stekel DJ, Git Y, Falciani F: The comparison of gene expression from multiple cDNA libraries. Genome Res 2000, 10(12):2055-2061.

56. Audic S, Claverie JM: The significance of digital gene expression profiles. Genome Res 1997, 7(10):986-995.

57. Romualdi C, Bortoluzzi S, D'Alessi F, Danieli GA: IDEG6: a web tool for detection of differentially expressed genes in multiple tag sampling experiments. Physiol Genomics 2003, 12(2):159-162.

58. Brandalise M, Severino FE, Maluf MP, Maia IG: The promoter of a gene encoding an isoflavone reductase-like protein in coffee (Coffea arabica) drives a stress-responsive expression in leaves. Plant Cell Rep 2009, 28(11):1699-1708.

59. van Loon LC, Rep M, Pieterse CM: Significance of inducible defenserelated proteins in infected plants. Annu Rev Phytopathol 2006, 44:135-162.

60. Sels J, Mathys J, De Coninck BM, Cammue BP, De Bolle MF: Plant pathogenesis-related (PR) proteins: a focus on PR peptides. Plant Physiol Biochem 2008, 46(11):941-950.

61. Carvalho Ade O, Gomes VM: Plant defensins-prospects for the biological functions and biotechnological properties. Peptides 2009, 30(5):1007-1020.

62. Zubini P, Zambelli B, Musiani F, Ciurli S, Bertolini P, Baraldi E: The RNA hydrolysis and the cytokinin binding activities of PR-10 proteins are differently performed by two isoforms of the Pru $\mathrm{p} 1$ peach major allergen and are possibly functionally related. Plant Physiol 2009, 150(3):1235-1247.

63. Ramiro DA, Escoute J, Petitot AS, Nicole M, Maluf MP, Fernandez D: Biphasic haustorial differentiation of coffee rust (Hemileia vastatrix race II) associated with defence responses in resistant and susceptible coffee cultivars. Plant Pathology 2009, 58(5):944-955.

64. Koshino LL, Gomes CP, Silva LP, Eira MT, Bloch C, Franco OL, Mehta A: Comparative proteomical analysis of zygotic embryo and endosperm from Coffea arabica seeds. J Agric Food Chem 2008, 56(22):10922-10926.

65. Botton A, Andreotti C, Costa G, Ramina A: Peach (Prunus persica L. Batsch) allergen-encoding genes are developmentally regulated and affected by fruit load and light radiation. J Agric Food Chem 2009, 57(2):724-734

66. Helleboid S, Hendriks T, Bauw G, Inze D, Vasseur J, Hilbert JL: Three major somatic embryogenesis related proteins in Cichorium identified as PR proteins. J Exp Bot 2000, 51(348):1189-1200.

67. Yasuda H, Nakajima M, Ito T, Ohwada T, Masuda H: Partial characterization of genes whose transcripts accumulate preferentially in cell clusters at the earliest stage of carrot somatic embryogenesis. Plant Mol Biol 2001, 45(6):705-712.

68. Rojas-Herrera R, Loyola-Vargas VM: Induction of a class III acidic chitinase in foliar explants of Coffea arabica L. during somatic embryogenesis and wounding. Plant Sci 2002, 163(4):705-711.

69. Borderies G, le Bechec M, Rossignol M, Lafitte C, Le Deunff E, Beckert M, Dumas C, Elisabeth MR: Characterization of proteins secreted during 
maize microspore culture: arabinogalactan proteins (AGPs) stimulate embryo development. Eur J Cell Biol 2004, 83(5):205-212.

70. Kragh KM, Hendriks T, de Jong AJ, Lo Schiavo F, Bucherna N, Hojrup P, Mikkelsen JD, de Vries SC: Characterization of chitinases able to rescue somatic embryos of the temperature-sensitive carrot variant ts 11. Plant Mol Biol 1996, 31(3):631-645.

71. van Hengel AJ, Guzzo F, van Kammen A, de Vries SC: Expression pattern of the carrot EP3 endochitinase genes in suspension cultures and in developing seeds. Plant Physiol 1998, 117(1):43-53.

72. Belkhadir Y, Subramaniam R, Dangl JL: Plant disease resistance protein signaling: NBS-LRR proteins and their partners. Curr Opin Plant Biol 2004 7(4):391-399

73. McHale L, Tan X, Koehl P, Michelmore RW: Plant NBS-LRR proteins: adaptable guards. Genome Biol 2006, 7(4):212.

74. Noir S, Combes MC, Anthony F, Lashermes P: Origin, diversity and evolution of NBS-type disease-resistance gene homologues in coffee trees (Coffea L.). Mol Genet Genomics 2001, 265(4):654-662.

75. Paal J, Henselewski H, Muth J, Meksem K, Menendez CM, Salamini F, Ballvora A, Gebhardt C: Molecular cloning of the potato Gro1-4 gene conferring resistance to pathotype Ro1 of the root cyst nematode Globodera rostochiensis, based on a candidate gene approach. Plant $J$ 2004, 38(2):285-297.

76. Eitas TK, Nimchuk ZL, Dangl JL: Arabidopsis TAO1 is a TIR-NB-LRR protein that contributes to disease resistance induced by the Pseudomonas syringae effector AvrB. Proc Natl Acad Sci USA 2008, 105(17):6475-6480.

77. Pan Q, Wendel J, Fluhr R: Divergent evolution of plant NBS-LRR resistance gene homologues in dicot and cereal genomes. J Mol Evol 2000, 50(3):203-213.

78. Tian Y, Fan $L$, Thurau T, Jung C, Cai D: The absence of TIR-type resistance gene analogues in the sugar beet (Beta vulgaris L.) genome. J Mol Evol 2004, 58(1):40-53.

79. DaMatta FM, Ramalho JDC: Impacts of drought and temperature stress on coffee physiology and production: a review. Brazil J Plant Physiol 2006, 18:55-81.

80. Cramer GR, Ergul A, Grimplet J, Tillett RL, Tattersall EA, Bohlman MC, Vincent D, Sonderegger J, Evans J, Osborne C, et al: Water and salinity stress in grapevines: early and late changes in transcript and metabolite profiles. Funct Integr Genomics 2007, 7(2):111-134.

81. Lu CM, Zhang JH: Effects of water stress on photosystem II photochemistry and its thermostability in wheat plants. J Exp Bot 1999, 50(336):1199-1206

82. Montavon P, Bortlik K: Evolution of robusta green coffee redox enzymatic activities with maturation. J Agric Food Chem 2004, 52(11):3590-3594.

83. Du YY, Wang PC, Chen J, Song CP: Comprehensive functional analysis of the catalase gene family in Arabidopsis thaliana. J Integr Plant Biol 2008, 50(10):1318-1326.

84. Montane $\mathrm{MH}$, Petzold B, Kloppstech K: Formation of early-light-inducibleprotein complexes and status of xanthophyll levels under high light and cold stress in barley (Hordeum vulgare L.). Planta 1999, 208(4):519-527.

85. Bruno $A K$, Wetzel CM: The early light-inducible protein (ELIP) gene is expressed during the chloroplast-to-chromoplast transition in ripening tomato fruit. J Exp Bot 2004, 55(408):2541-2548.

86. Canel C, Bailey-Serres JN, Roose ML: Pummelo fruit transcript homologous to ripening-induced genes. Plant Physiol 1995, 108(3):1323-1324.

87. Padmanabhan V, Dias DM, Newton RJ: Expression analysis of a gene family in loblolly pine (Pinus taeda L.) induced by water deficit stress. Plant Mol Biol 1997, 35(6):801-807.

88. Teale WD, Paponov IA, Palme K: Auxin in action: signalling, transport and the control of plant growth and development. Nat Rev Mol Cell Biol 2006, 7(11):847-859.

89. Staswick PE, Serban B, Rowe M, Tiryaki I, Maldonado MT, Maldonado MC, Suza W: Characterization of an Arabidopsis enzyme family that conjugates amino acids to indole-3-acetic acid. Plant Cell 2005, 17(2):616-627.

90. Dahlke Rl, Luethen H, Steffens B: ABP1: An auxin receptor for fast responses at the plasma membrane. Plant Signal Behav 2010, 5(1)

91. Matsubayashi Y, Sakagami Y: Peptide hormones in plants. Annu Rev Plant Biol 2006, 57:649-674.

92. Pearce G, Moura DS, Stratmann J, Ryan CA Jr: RALF, a 5-kDa ubiquitous polypeptide in plants, arrests root growth and development. Proc Natl Acad Sci USA 2001, 98(22):12843-12847.
93. Matos JL, Fiori CS, Silva-Filho MC, Moura DS: A conserved dibasic site is essential for correct processing of the peptide hormone AtRALF1 in Arabidopsis thaliana. FEBS Lett 2008, 582(23-24):3343-3347.

94. Srivastava R, Liu JX, Guo H, Yin Y, Howell SH: Regulation and processing of a plant peptide hormone, AtRALF23, in Arabidopsis. Plant J 2009, 59(6):930-939.

95. Fusaro AF, Sachetto-Martins G: Blooming time for plant glycine-rich proteins. Plant Signal Behav 2007, 2(5):386-387.

96. Mangeon A, Junqueira RM, Sachetto-Martins G: Functional diversity of the plant glycine-rich proteins superfamily. Plant Signal Behav 2010, 5(2):99-104.

97. Park AR, Cho SK, Yun UJ, Jin MY, Lee SH, Sachetto-Martins G, Park OK: Interaction of the Arabidopsis receptor protein kinase Wak1 with a glycine-rich protein, AtGRP-3. J Biol Chem 2001, 276(28):26688-26693.

98. Domingo C, Sauri A, Mansilla E, Conejero V, Vera P: Identification of a novel peptide motif that mediates cross-linking of proteins to cell walls. Plant J 1999, 20(5):563-570

99. Margis R, Reis EM, Villeret V: Structural and phylogenetic relationships among plant and animal cystatins. Arch Biochem Biophys 1998, 359(1):24-30

100. Martinez M, Diaz I: The origin and evolution of plant cystatins and their target cysteine proteinases indicate a complex functional relationship. BMC Evol Biol 2008, 8:198.

101. Rivard D, Girard C, Anguenot R, Vezina LP, Trepanier S, Michaud D: MsCYS1, a developmentally-regulated cystatin from alfalfa. Plant Physiol Biochem 2007, 45(6-7):508-514.

102. Martinez M, Cambra I, Carrillo L, Diaz-Mendoza M, Diaz I: Characterization of the entire cystatin gene family in barley and their target cathepsin Llike cysteine-proteases, partners in the hordein mobilization during seed germination. Plant Physiol 2009, 151(3):1531-1545.

103. Kordis D, Turk V: Phylogenomic analysis of the cystatin superfamily in eukaryotes and prokaryotes. BMC Evol Biol 2009, 9:266.

104. Rawlings ND, Barrett AJ, Bateman A: MEROPS: the peptidase database. Nucleic Acids Res 2010, , 38 Database: D227-233.

105. Srinivasan T, Kumar KR, Kirti PB: Constitutive expression of a trypsin protease inhibitor confers multiple stress tolerance in transgenic tobacco. Plant Cell Physiol 2009, 50(3):541-553.

106. De Maria CAB, Trugo LC, Aquino Neto FR, Moreira RFA, Alviano CS: Composition of green coffee water-soluble fractions and identification of volatiles formed during roasting. Food Chem 1996, 55:203-207.

107. Leloup V, Louvrier A, Liardon R: Degradation mechanisms of chlorogenic acids during roasting. Proc Internat Congr ASIC 1995, 16:192-198.

108. Fischer M, Reimann S, Trovato V, Redgwell RJ: Polysaccharides of green Arabica and Robusta coffee beans. Carbohydr Res 2001, 330(1):93-101.

109. Marraccini P, Rogers WJ, Allard C, Andre ML, Caillet V, Lacoste N, Lausanne F, Michaux S: Molecular and biochemical characterization of endo-beta-mannanases from germinating coffee (Coffea arabica) grains. Planta 2001, 213(2):296-308.

110. Redgwell RJ, Trovato V, Curti D, Fischer M: Effect of roasting on degradation and structural features of polysaccharides in Arabica coffee beans. Carbohydr Res 2002, 337(5):421-431.

111. Kasai N, Konishi A, Iwai K, Maeda G: Efficient digestion and structural characteristics of cell walls of coffee beans. J Agric Food Chem 2006, 54(17):6336-6342.

112. Pre M, Caillet V, Sobilo J, McCarthy J: Characterization and expression analysis of genes directing galactomannan synthesis in coffee. Ann Bot 2008, 102(2):207-220

113. Somerville C: Cellulose synthesis in higher plants. Annu Rev Cell Dev Biol 2006, 22:53-78

114. Richmond TA, Somerville CR: The cellulose synthase superfamily. Plant Physiol 2000, 124(2):495-498.

115. Liepman AH, Nairn CJ, Willats WG, Sorensen I, Roberts AW, Keegstra K: Functional genomic analysis supports conservation of function among cellulose synthase-like a gene family members and suggests diverse roles of mannans in plants. Plant Physiol 2007, 143(4):1881-1893.

116. Cocuron JC, Lerouxel O, Drakakaki G, Alonso AP, Liepman AH, Keegstra K, Raikhel N, Wilkerson CG: A gene from the cellulose synthase-like C family encodes a beta-1,4 glucan synthase. Proc Natl Acad Sci USA 2007, 104(20):8550-8555.

117. Arya M, Rao L: An impression of coffee carbohydrates. Crit Rev Food Sci Nutr 2007, 47(1):51-67.

118. Chahan Y, Jordon A, Badoud R, Lindinger W: From the green bean to the cup of coffee:investing coffee roasting by on-line monitoring of volatiles. Eur Food Res Technol 2002, 214:92-104. 
119. Helentjaris T, Bate NJ, Allen SM: Novel invertase inhibitors and methods of use. Patent WO/2001/058939. USA 2001.

120. Bate NJ, Niu X, Wang Y, Reimann KS, Helentjaris TG: An invertase inhibitor from maize localizes to the embryo surrounding region during early kernel development. Plant Physiol 2004, 134(1):246-254.

121. Lehle $L$, Tanner $W$ : The function of myo-inositol in the biosynthesis of raffinose. Purification and characterization of galactinol:sucrose 6galactosyltransferase from Vicia faba seeds. Eur J Biochem 1973, 38(1):103-110.

122. Rogers WJ, Michaux S, Bastin M, Bucheli P: Changes to the content of sugars, sugar alcohols, myo-inositol, carboxylic acids and inorganic anions in developing grains from different varieties of Robusta (Coffea canephora) and Arabica (C. arabica) coffees. Plant Sci 1999, 149(2):115-123.

123. Chabrillange N, Dussert S, Engelmann F, Doulbeau S, Hamon S: Desiccation tolerance in relation to soluble sugar contents in seeds of ten coffee (Coffea L.) species. Seed Sci Res 2000, 10(3):393-396.

124. Peters S, Mundree SG, Thomson JA, Farrant JM, Keller F: Protection mechanisms in the resurrection plant Xerophyta viscosa (Baker): both sucrose and raffinose family oligosaccharides (RFOs) accumulate in leaves in response to water deficit. J Exp Bot 2007, 58(8):1947-1956.

125. Nishizawa A, Yabuta Y, Shigeoka S: Galactinol and raffinose constitute a novel function to protect plants from oxidative damage. Plant Physiol 2008, 147(3):1251-1263.

126. Marraccini $P$, Rogers WJ, Caillet V, Deshayes A, Granato D, Lausanne F, Lechat S, Pridmore D, Petiard V: Biochemical and molecular characterization of alpha-D-galactosidase from coffee beans. Plant Physiol Biochem 2005, 43(10-11):909-920.

127. Gruber CW, Cemazar M, Heras B, Martin JL, Craik DJ: Protein disulfide isomerase: the structure of oxidative folding. Trends Biochem Sci 2006, 31(8):455-464

128. Alvarez C, Calo L, Romero LC, Garcia I, Gotor C: An O-acetylserine(thiol) lyase homolog with L-cysteine desulfhydrase activity regulates cysteine homeostasis in Arabidopsis. Plant Physiol 2010, 152(2):656-669.

129. Marraccini P, Deshayes A, Petiard V, Rogers WJ: Molecular cloning of the complete $11 \mathrm{~S}$ seed storage protein gene of Coffea arabica and promoter analysis in transgenic tobacco plants. Plant Physiol Biochem 1999, 37(4):273-282.

130. Aerts RJ, Baumann TW: Distribution and Utilization of Chlorogenic Acid in Coffea Seedlings. J Exp Bot 1994, 45(273):497-503.

131. Ky CL, Louarn J, Dussert S, Guyot B, Hamon S, Noirot M: Caffeine, trigonelline, chlorogenic acids and sucrose diversity in wild Coffea arabica L. and C. canephora. Food Chem 2001, 75:223-230.

132. Stadler RH, Varga N, Milo C, Schilter B, Vera FA, Welti DH: Alkylpyridiniums. 2. Isolation and quantification in roasted and ground coffees. J Agric Food Chem 2002, 50(5):1200-1206

133. Mazzafera P: Catabolism of caffeine in plants and microorganisms. Front Biosci 2004, 9:1348-1359.

134. Baudet C, Dias Z: New EST Trimming Procedure Applied to SUCEST Sequences. Advances in Bioinformatics and Computational Biology, Proceedings 2007, 57-68.

135. Nei M, Gojobori T: Simple Methods for Estimating the Numbers of Synonymous and Nonsynonymous Nucleotide Substitutions. Mol Biol Evol 1986, 3(5):418-426.

136. Eisen MB, Spellman PT, Brown PO, Botstein D: Cluster analysis and display of genome-wide expression patterns. Proc Natl Acad Sci USA 1998, 95(25):14863-14868.

doi:10.1186/1471-2229-11-30

Cite this article as: Mondego et al: An EST-based analysis identifies new genes and reveals distinctive gene expression features of Coffea arabica and Coffea canephora. BMC Plant Biology 2011 11:30.

\section{Submit your next manuscript to BioMed Central and take full advantage of:}

- Convenient online submission

- Thorough peer review

- No space constraints or color figure charges

- Immediate publication on acceptance

- Inclusion in PubMed, CAS, Scopus and Google Scholar

- Research which is freely available for redistribution

Submit your manuscript at www.biomedcentral.com/submit
Ciomed Central 